\title{
DE RELIQUIAS OCULTAS: SOBRE LA CAPILLA DEL PILAR DE ZARAGOZA, DE SANTIAGO APÓSTOL A VENTURA RODRÍGUEZ ${ }^{1}$
}

Fernando Marías

José Riello

Universidad Autónoma de Madrid

ORCID:https://orcid.org/0000-0003-1943-5525

ORCID:https://orcid.org/0000-0002-0734-7731

\section{RESUMEN}

Cuando en 1750 Ventura Rodríguez se hizo cargo del proyecto para construir la nueva Capilla de la Virgen del Pilar en su basílica zaragozana, sabía que su nueva epidermis de materiales nobles ocultaría otra fábrica, no por más modesta menos importante: la "Pared antigua de la primitiva Santa Capilla edificada por Santiago". Aún hoy se abre en el muro occidental de la Capilla un pequeño orificio que permite ver, tocar y besar lo que los fieles piensan que sea la columna mariana, pero que en origen quizá debió ser más propiamente la pared apostólica. Así pues, ¿un Santiago arquitecto de una construcción tan antigua como ocultada, protagonista de una leyenda que no ha llegado a entreverarse con la del Santiago de Compostela, a donde llegó muerto? Este artículo intenta reconstruir este episodio y deconstruir esta tradición aragonesa.

Palabras clave: Santiago apóstol, capilla de Nuestra Señora del Pilar, Zaragoza, Ventura Rodríguez, reliquias

\section{ABSTRACT}

When, in 1750, Ventura Rodríguez accepted a commission to build the new chapel of the Virgin of the Pillar at the Cathedral-Basilica of Our Lady of the Pillar in Zaragoza, he knew that its new covering of fine materials would conceal another modest but very important construction: the "Pared antigua de la primitiva Santa Capilla edificada por Santiago" (the old Wall of the original and Holy Chapel built by Saint James). A small hole exists to this day on the western wall of the chapel, allowing people to see, touch and kiss what the faithful believe to be the Marian column, but which in origin must, perhaps, have been the apostolic wall of the first shrine. So, is St James the Great the architect of a construction that is as old as the time for which it has been concealed, the central figure of a legend that has never been interlinked with that Santiago de Compostela, where his corpse was taken? This article attempts to reconstruct the episode while also deconstructing this Aragonese tradition.

Keywords: Saint James the Great, chapel of the Virgen del Pilar, Zaragoza, Ventura Rodríguez, relics

La corografía urbana, en su versión incluso gráfica, ha seguido pautas que exigían un elogio y una descripción de las ciudades, y una represen- tación en estas últimas, tanto de la urbs material y arquitectónica como de la civitas en tanto que imagen de la colectividad ciudadana. Este segundo 
tipo de imágenes, comunicéntricas por decirlo con Richard L. Kagan², combinaba la ciudad real con la imaginada y querida, representada por sus dones naturales y sus frutos, sus devociones y creencias, sus dioses tutelares o sus santos protectores y más representativos, por ejemplo, de la antigüedad de su cristianía y sus iglesias. Lienzos como la Vista y plano de Toledo (ca. 1600, Toledo, Museo del Greco) de Dominico Theotocópuli 'El Greco' constituyen ejemplos señalados de esta forma particular y doble de evocar la Ciudad imperial, con la vista y la planta de la misma y con las representaciones personificadas del río Tajo y sus riquezas y de la "santidad" de la iglesia de Toledo, representada de forma metafórica por la Descensión de la Virgen para imponer la casulla al arzobispo y futuro santo Ildefonso, piedra basilar de la predilección mariana hacia su templo que dejaría su propia impronta sobre el suelo de la ciudad.

Es evidente que no solo la iglesia de Toledo, primada de las Españas, y su ciudad podían vanagloriarse de este reconocimiento sobrenatural, pues Zaragoza podía rivalizar con ella, presentándose como la ciudad que había recibido tal don con cinco siglos de adelanto, y donde se había erigido la primera iglesia dedicada a María no solo de España, sino de toda la Cristiandad. En paralelo, la aparición de la Virgen del Pilar sobre su columna debió de ser lugar común en las corografías de Zaragoza, tal como han demostrado la restauración de la Vista de Zaragoza de Juan Bautista Martínez del Mazo (1645-1647, Madrid, Museo del Prado) y una versión menos conocida (Zaragoza, colección particular)³, dando polícroma visibilidad a esta protección incluso antes de que tales imágenes llegaran a la esfera pública de la estampa, ya fueran del milagro de la primera Descensión como de las imágenes urbanas de la antigua Cesaraugusta de época romana y moderna.

Como veremos, durante la Edad Media se establecieron unas rivalidades entre diferentes sedes episcopales que buscaron su legitimación y su primacía en la historia de su antigüedad tanto como en la mitografía de sus leyendas. De hecho, algunas ciudades podían competir en sus pretensiones de ser consideradas como sede primada gracias a la presencia apostólica de Santiago el Mayor: Toledo, Santiago de Compostela, Sevilla,
Tarragona y Braga ${ }^{4}$, quizá Cartagena. También durante la Época Moderna se reforzaron las iniciativas hagiográficas, en un momento en que, al mismo tiempo, se ponía en duda la intervención del apóstol en la batalla de Clavijo por parte de los cardenales Roberto Belarmino y Cesare Baronio, quien se basaba en la Collectio conciliorum (1593) del futuro arzobispo de Toledo García de Loaysa y su comisión pontificia para revisar el Breviario romano, pero también se podían añadir otras razones.

Además, la defensa del Hijo del Trueno se imbricaba con la de la Inmaculada Concepción de la Virgen María en un contexto de discusión encendida y de ficciones como las granadinas del Sacromonte, propiciadas por los moriscos de la ciudad. Santiago habría oficiado en Granada la primera misa rodeado de sus discípulos árabes y futuros mártires; si el fabulador Jerónimo Román de la Higuera (1538-1611), en sus manuscritos, y el condestable de Castilla Juan Fernández de Velasco, en sus Dos discursos en los que se defiende la venida y predicación del Apóstol Santiago en España (Valladolid, 1605), se convirtieron en escudos de la tradición, frente a los prudentes escritos de Juan de Mariana o Pedro de Valencia, Román de la Higuera se presentó a su vez como paladín de la "verdadera descensión de la Madre de Dios a esta Santa Iglesia [Catedral] de Toledo", pero también en este momento, y como culminación de una tradición ya asentada documentalmente por el mismo Francisco de Pisa, se estaba construyendo en dicho Templo Primado ese "pequeño Escorial" que era un santuario -capilla, ochavo, sacristía, patios, dependencias - construido en torno a la patrona toledana, la Virgen del Sagrario5. En este contexto, el jesuita Juan de Mariana (1536-1624), en su difundida Historia de España6, ya había alzado su autorizada voz, que precedió a los debates de 1627 sobre el patronato de España y su monopolio por parte de Santiago?

No deja de ser significativa la interrelación de tales episodios, fundacionales medievales o críticos desde el humanismo católico de la Contrarreforma romana o desde una llustración algo más laica, en la historia interurbana de las leyendas y las reliquias marianas y apostólicas. Unas ciudades se espejaban, se emulaban y se veían provocadas por las iniciativas de otras, esca- 
pando incluso a lo que podrían ser solo productos del orgullo local.

\section{Un dibujo de Ventura Rodríguez}

Cuando en 1750 Ventura Rodríguez se hizo cargo del proyecto de la nueva Capilla de la Virgen del Pilar en su basílica zaragozana, era plenamente consciente de que por debajo de su nueva epidermis de materiales nobles se ocultaría otra fábrica, no por más modesta menos importante. Hoy quizá lo hayamos olvidado, pero todavía nuestro arquitecto señaló en su planta que, por debajo de su piel dieciochesca, estaba la "Pared antigua de la primitiva Sta Capilla edificada por Santiago" (fig. 1). Esa pared también aparece en los dibujos preparatorios del Legado de Silvestre Pérez de 1825, que hoy se conserva en la Real Academia de San Fernando?.

Aún hoy se abre en el muro occidental de la Capilla un pequeño orificio que permite ver, tocar y besar lo que los fieles piensan que sea la columna mariana, pero que quizá debiera haber sido originalmente, de no haberse tocado, la pared apostólica (figs. 2 y 3$)^{10}$. No sabemos si esta zona baja fue retocada en las fechas de ejecución del trasaltar de Carlos Salas Vilaseca (1767-1768) y la decoración del Coreto de la Virgen (1771-1772)"1, pero los dibujos de Ventura Rodríguez parecerían confirmarlo; de hecho, uno del escultor y arquitecto Gregorio Sevilla Cavarga (ca. 1742-1782)'12, de 23 de junio de 1774'13, que modificaba el plano 3 de Ventura Rodríguez, presentaba una variante, aun no modificándose el sitio de la adoración del santo Pilar, que responde a lo que hoy podemos ver en el lado occidental de la Capilla: "indudablemente se hizo la variación de acuerdo con él". Se introdujo un arco y, en él, el círculo dentro de un óvalo, en lugar del único círculo que correspondería con la apertura moderna ovalada de los revestimientos (E, "adoración nueva") y no la antigua circular (D, "adoración antigua") de un diseño de Julián Yarza del que luego hablaremos (fig. 4).

Así pues, ¿podría tratarse de un Santiago arquitecto de una construcción tan antigua como ocultada, y protagonista de una leyenda que no ha llegado a entreverarse con la del Santiago compostelano, llegado muerto a Galicia y por lo tanto inactivo ${ }^{14}$ Este ensayo intenta re-construir este episodio y, como corolario involuntario, deconstruir esta tradición aragonesa.

\section{La tradición mitográfica}

La primera mención conocida de la llegada a Hispania de Santiago Zebedeo está fechada hacia el año 600, con el Breviarium Apostolorum ("Hic [Santiago] Hispaniœ occidentalia loca predicat"), y de haber sido enterrado en una "Sepultus est in Achaia Marmarica", un texto redactado entre la Galia e Italia. Aunque no apareciera en De orto et obitu patrum (ca. 750) de San Virgilio de Salzburgo (ca. 700-784)15, escrito en el sudeste de Germania, lo enterraba también en "aca marca"/"Achaia marmarica"16, esté donde esté tal lugar; en consecuencia, no habría existido noticia alguna al respecto durante nada menos que seis siglos, desde ese legendario 2 de enero de 40 en el que habría tenido la Descensión de la Virgen en Cesaraugusta y la supuesta fecha de su defunción en Jerusalén, el año 44.

Así pues, como es bien sabido, todo parece indicar que se trataría de una invención - a partir del anglosajón Aldhelmo de Malmesbury (ca. 639709) o del irlandés Virgilio- de la época del rey Mauregato de Asturias (783-789), tras deponer a Alfonso II, en cuyo tiempo se escribió el himno O rex regum u O Dei verbum, quizá por Beato de Liébana (ca. 730-ca. 804)17. Es en este texto en el que se menciona por vez primera una venida a España del Hijo del Trueno, con la posterior adición - a partir del siglo IX, momento en el que un autor fundió esta tradición con la de Santiago en la Translatio S. lacobi in Hispaniam ${ }^{18}$ - de la llegada de los tres (Tessefor, Torcuato y Atanasio) o los siete varones apostólicos (Torcuato, Segundo, Endalecio, Tisefón, Eufrasio, Cecilio e Ysicio) ${ }^{19}$.

Por su parte, Alfonso II el Casto (ca. 760-789842), favoreció la creencia del entierro en Iria Flavia o Compostum -más que el mítico Campus stellae- del apóstol, ejecutado en 44 durante el reinado de Herodes Agripa o Agripa I, tras el hallazgo de un cuerpo entre 818 y $842^{20}$, en tiempos del obispo Teodemiro (†847).

No es seguro que en este final del siglo VIII se añadiera la leyenda del desfallecimiento de Santiago en Zaragoza, y de la aparición de la Virgen María sobre un pilar o columna para fortalecerlo 


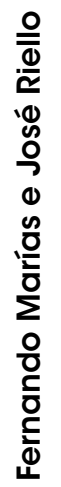
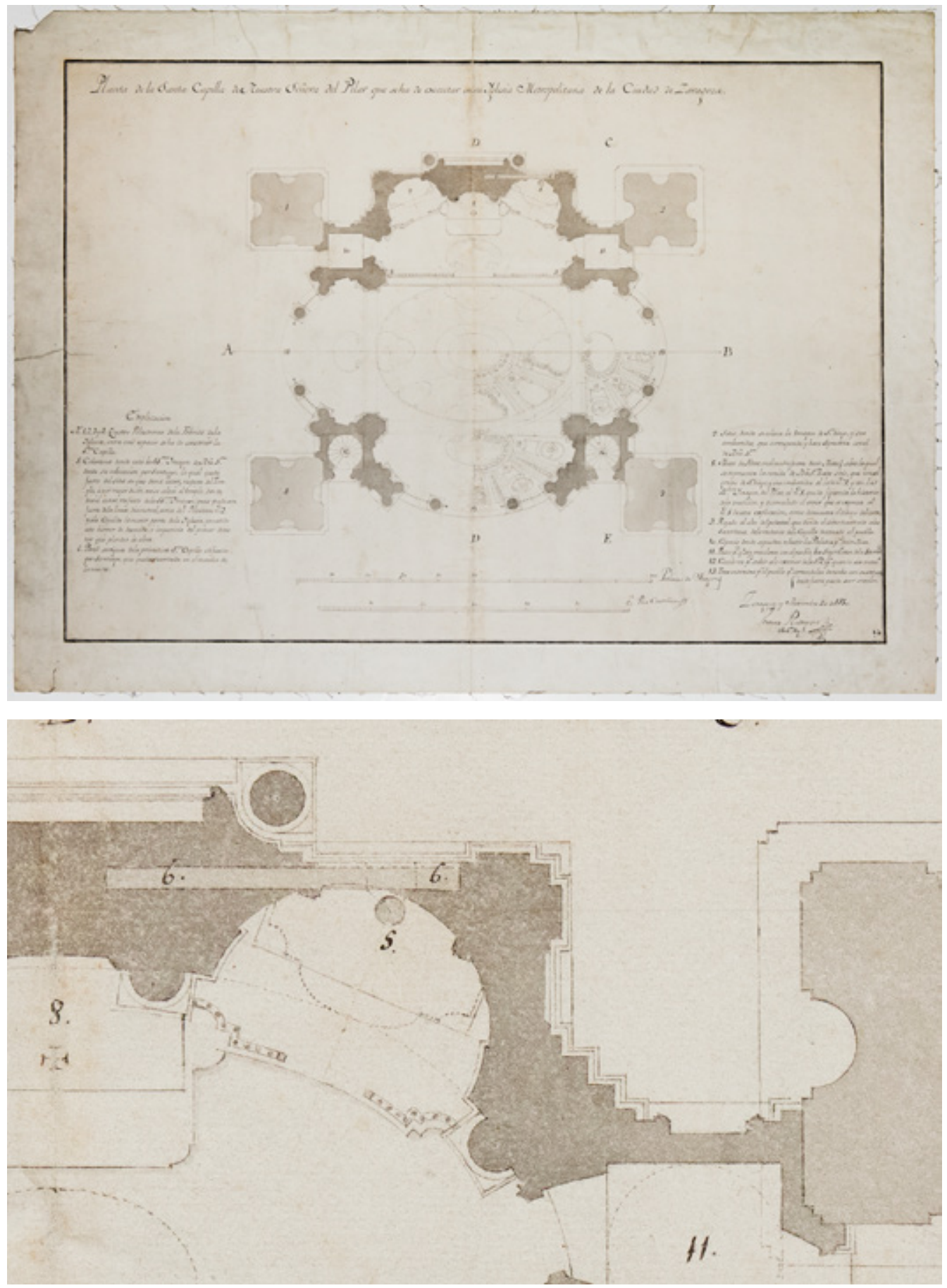

Fig. 1 a y b. Ventura Rodríguez, Planta de la Santa Capilla de Nuestra Señora del Pilar que se ha de executar en su Iglesia Metropolitana de la Ciudad de Zaragoza. Zaragoza, 20 de noviembre de 1750, 480 × 680 mm. Zaragoza, Archivo del Cabildo Metropolitano, sin signatura 


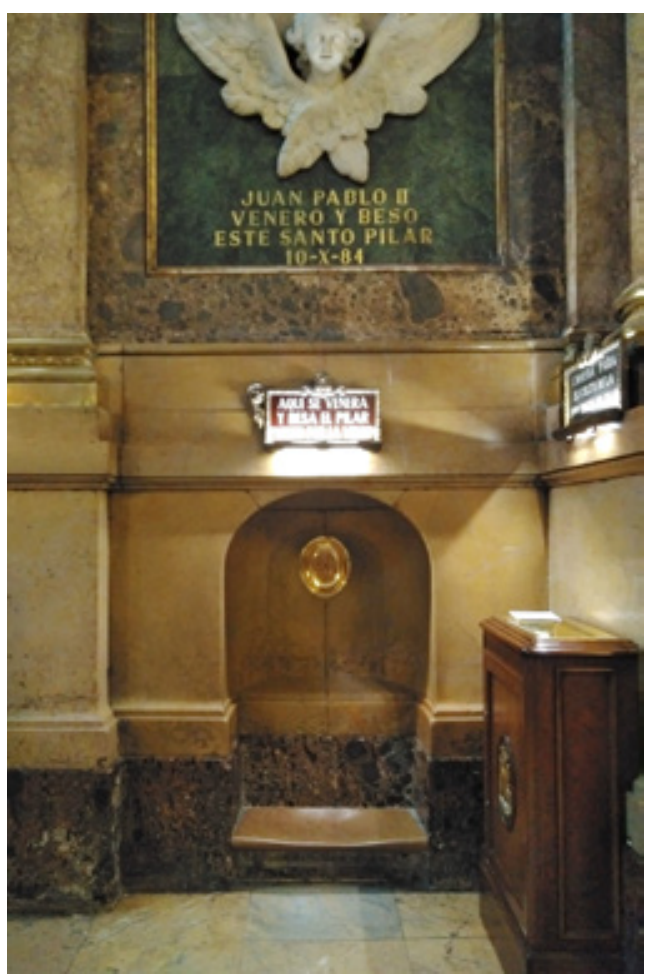

Fig. 2. Humilladero de la Capilla de Nuestra Señora del Pilar. Fotografía: José Riello

en su actividad de predicación. El primer testimonio de estos acontecimientos habría sido el códice de las "Moralia in Job" (578-595) de San Gregorio Magno, de finales del siglo XIII o comienzos del XIV, evidentemente interpolado por entonces $^{21}$. Al margen de la leyenda del obispo visigodo [San] Braulio (631-651), quien habría construido ya un primer templo, aunque nada dijera [San] Eugenio (ca. 595-646-657) en su visita a Zaragoza en 643-64522, todo parece remitirse a la actividad del primer obispo, tras la reconquista de la ciudad, Pedro de Librana. Éste podría haber fomentado, o incluso creado, la leyenda, quizá como alternativa a la creciente importancia concedida a la Descensión de la Virgen, en Toledo, para entregar la casulla a un San Ildefonso, que había defendido el carácter inmaculado de su concepción, más que para rivalizar con Santiago de Compostela ${ }^{23}$. Sin embargo, a mediados del siglo XVII también se adujo el testimonio de un obispo godo de Zaragoza, Tayón (646-659)

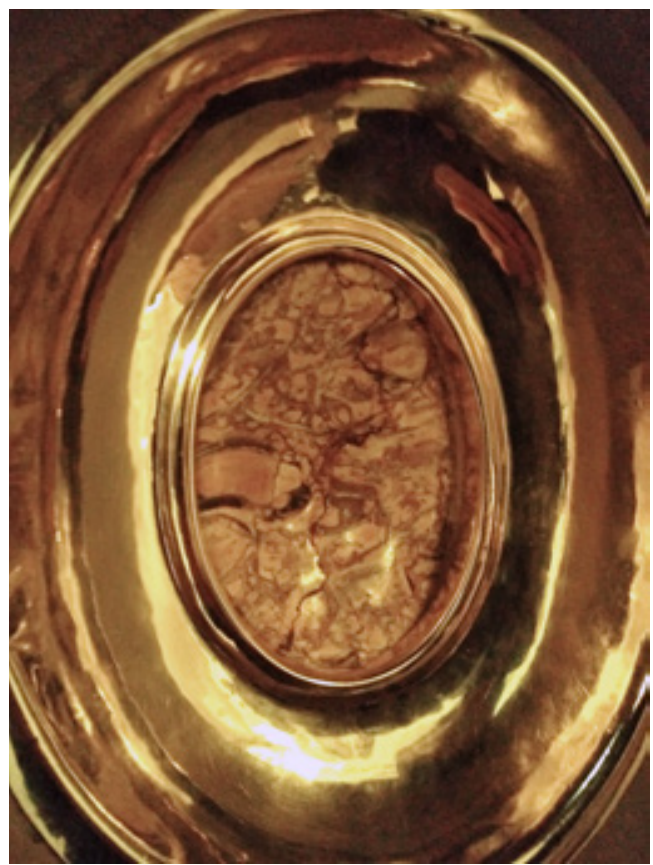

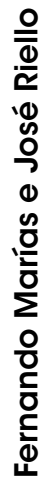

Fig. 3. Detalle de fig. 2. Fotografía: José Riello

[Samuel Tajón (ca. 600-680)]; su relación sobre la venida de la Virgen y la construcción de la capilla por parte de Santiago, basada supuestamente en un texto de Atanasio discípulo, compañero del Zebedeo y primer obispo de la ciudad, la comentaría Luis López [Vaca] en su tratado Pilar de Zaragoza, columna firmíssima de la fe de España (Zaragoza, María Fernández, 1649)24.

No podemos olvidar que, en Toledo, del altar de la Descensión de la Virgen no se tienen testimonios hasta 1207, y de la imagen hasta 1215; y que las primeras noticias de una defensa del milagro de la Descensión y la casulla de San Ildefonso son de tiempos del arzobispado de Rodrigo Jiménez de Rada durante el IV Concilio Lateranense (1215, vinculándose al tema de la primacía de la sede toledana), recibiendo un importante impulso al elegir Enrique II este sitio para su entierro de 1374 y el de la futura dinastía de los reyes Trastámara.

\section{Vestigios materiales}

Si nos ocupamos no solo de textos, sino también de una fábrica material, tenemos noticias de 

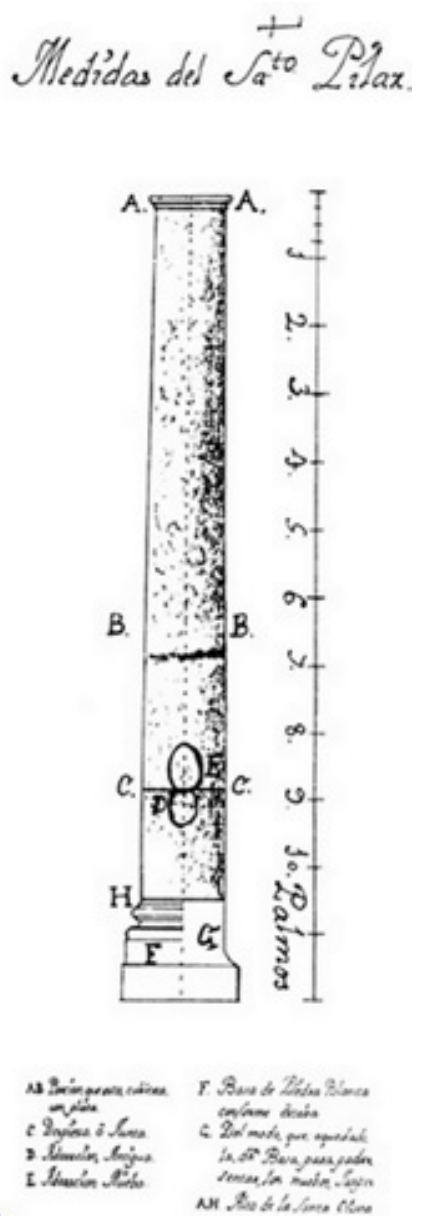

Fig. 4. Julián Yarza, Medidas del Santo Pilar, 13-14 de septiembre de 1756. Zaragoza, Archivo del Cabildo Metropolitano, sin signatura

la existencia en Zaragoza de una iglesia dedicada a Santa María - a secas - supuestamente desde el siglo IX25, e hipotéticos testimonios arqueológicos - restos "mozárabes" de alabastro- desde el $X$, anteriores a la conquista de Alfonso I $(1118)^{26}$. Silencio absoluto en los poemas de Eugenio de Toledo en 643-64527, ni documentos o restos de época visigoda ${ }^{28}$. Todo ello parece demasiado poco para un edificio supuestamente levantado desde la primera mitad del siglo I, pero del que no existió memoria alguna hasta como mucho los siglos IX o X, en un momento de dominio musulmán de la ciudad y pocas noticias, por no decir ninguna, sobre la comunidad mozárabe de Zaragoza29.
En el siglo XII, los obispos Pedro de Librana y Pedro Tarroja acometieron su reparación y reconstrucción, tal vez concluida hacia 1241, un siglo después de su reconocimiento pontificio como colegiata, en 1141 por parte de Inocencio II. Para entonces estaba la Capilla del Pilar junto a un cantón o ángulo, quizá de la muralla junto al río Ebro, en el claustro, fuera del recinto de la iglesia. Aparentemente estaba ya en estado ruinoso, y el obispo Hugo de Mataplana acometió en 1293 su reconstrucción, datando de 1299 el primer documento en que se cita una advocación de Santa María del Pilar (como en la Apparitio b. Mariae de Pilari), y quizá incluso el inicio oficial de su culto ${ }^{30}$.

Entre 1434 y 1435 un importante incendio dañó la Capilla, y su techumbre de madera fue sustituida por una bóveda de crucería, siguiéndose una reconstrucción de la iglesia, de única nave y formalización latericia, cerrada probablemente con un "portal y portegado" de 1492; a ella se añadió un nuevo retablo de Damián Forment realizado entre 1509 y $1518^{31}$. El médico de Núremberg, Hieronymus Münzer, que la visitó en 1495, halló que "habet ítem Cesaraugusta preclaram ecclesiam ad Sanctam Mariam dictam. In qua in una cripta Beata Maria illis diebus magna fecit miracula. El lucent ibi plures argentee lampades die noctesque" ${ }^{32}$.

Mucho después, en 1766, el canónigo Aramburu de la Cruz identificaba los restos, que él mismo había visto desmontar a mediados del siglo XVIII, con los de la Capilla del Pilar del obispo Librana, aunque es más probable que fuera la Capilla del siglo XV si nos fiamos de los arcos de medio punto, las crucerías y el retablo de Forment que se ven en el dibujo de 1725, 1732 o 1737 (fig. 5) 33: $^{3}$

... se haría con las Columnas, y Arcos de piedra, que hemos alcanzado, y la techumbre de madera a lo Mosayco, que quisieron se huviesse hecho entonces Luis López [Vaca] [1639] $]^{34}$, y el P. Hebrera [José Antonio de Hebrera y Esmir OFM (16521719) $3^{35}$, pues hasta nuestros días, y hasta que se han derrivado han passado seiscientos años... hay menos dificultad para que se haya mantenido al menos la Obra de Piedra desde que la reparó Don Pedro Librana hasta su demolición, que hemos visto $^{36}$. 


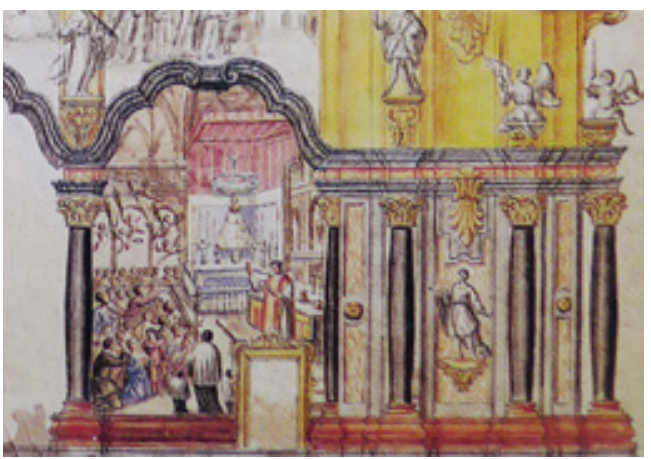

Fig. 5. Domingo Yarza (?), Detalle de la Santa Capilla de Nuestra Señora del Pilar, 1725, 1732 o 1737. Tinta y aguada sobre papel, 570 x 730 mm. Zaragoza, Archivo del Cabildo Metropolitano, sin signatura

No parece que en 1616 el franciscano Diego Murillo (1555-1616) se refiriera a la estructura material de la Capilla ${ }^{37}$, más allá de que se cubrieron las tapias para protegerlas de los ladrones de reliquias. Sin embargo, poco después, en 1639, Luis López abordó de lleno este tema; señaló que, en unas obras ejecutadas en 1519, se había hallado una pared que podría identificarse con la original que habían construido Santiago y sus compañeros con la colaboración de diferentes vecinos que allí se habían reunido y habían recogido

suficientes materiales de cal, piedra, y madera, para hacer la Capilla de quatro tapias de tierra, y piedra, cubierta de madera, como parece por dos pedaços de tapia, que advertidamente dexaron descubiertos en la parte que adoramos del bendito Pilar quando se acabó la Capilla en la forma que oy está, que según acredita la tradición son parte de aquellas quatro paredes que el Apóstol Santiago y sus discípulos edificaron por sus manos, no sin muchos Ángeles que ayudarían, y los demás fieles que ministraron la obra. La grandeza que tuvo fue diez y seis pies de largo, y ocho de ancho, como se venera dividida de la Capilla grande...

Ya en 1719, el Padre Hebrera enriqueció esta historia, pues habría sido "el mismo Dios quien hizo la Planta; el Cielo, quien dio la adorable CoIona para el Fundamento; las Sagradas Inteligencias, las que labraron la Divina Imagen ${ }^{38}$, para la adoración ${ }^{39}$; la Soberana Reyna, la que vino en carne mortal, y eligió el sitio; los Ángeles, y el Santo Apóstol San Tiago con sus Discípulos, los que hizieron la Obra, y ella salió tan escorçada, y

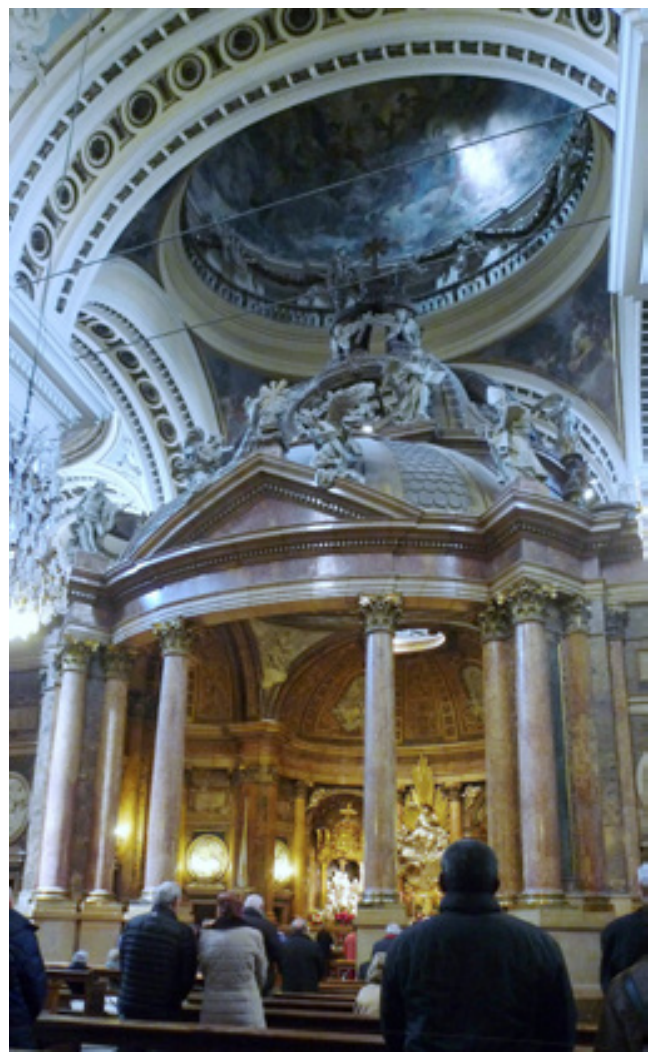

Fig. 6. Santa Capilla de Nuestra Señora del Pilar. Fotografía: Fernando Marías

reducida, como a no pasar su longitud de diez y seis passos, y su latitud de ocho".

En aquella fecha, y tras el añadido de la llamada reja de Constantino y la renovación de la bóveda, se mantenía todavía "sin mudança alguna... como un Diamante finíssimo, en el centro de una grande Joya" que era, para entonces, la nueva basílica diseñada por Francisco Herrera el Mozo40; por ello, la "Academia" [Particular de dibujo de Zaragoza creada en 1714] tendría que resolver el problema de "dilatar una Capilla muy angosta sin demudarla, ni destruirla, y hazerla parecer, y ser en la realidad, un Magnífico Templo, como éste de Zaragoza".

Por su parte, como señaló Aramburu en 1766, derribada la vieja estructura de 16 por 8 palmos - a partir de la medida tomada por el viajero quinientista Gaspar Barreiros ${ }^{41}$ — entre el 1 y el 2 de noviembre de 1754, fue puesta la primera 
piedra el 3 de diciembre con asistencia del obispo Francisco Añoa y Busto, e inaugurada la nueva Capilla el 12 de octubre de 1765 (fig. 6). Ventura Rodríguez había situado el altar en el lado occidental, modificando la orientación antigua, hacia el norte, del mismo, decisión tomada en Zaragoza en octubre de 1754, para ubicar la Virgen del Pilar en un nuevo lugar.

En efecto, en noviembre, según un testigo presencial de los hechos recogidos de forma manuscrita, se habría procedido a "desmontar la cabeza de la fábrica vieja", al dorso del Santo Pilar ${ }^{42}$. Se quitó "una porción de la fábrica de la Santa Capilla, de la misma que los Ángeles con Santiago construyeron... que está encerrada entre dos paredes de cantería, y es una pasta de tierra sola sin yeso, ni cal ni otra mezcla a manera de adobas"; de inmediato, el capellán la guardó para distribuirla entre los devotos como una preciosa reliquia ${ }^{43}$.

Nada se precisaba en el texto de Aramburu, aunque previamente había afirmado que, aunque la columna había sido respetada por las llamas de 1435, habían desaparecido dos de las paredes "que entonces aún se conservaban de las que edificó San-Tiago...", pero habían permanecido dos"4, aunque el fuego había "... desfigurado aquellas sagradas paredes". Aramburu repasa la bibliografía previa - Murillo y López-y concluye que para 1616 solo quedaban dos paredes que se cubrieron, dejándose solo visibles dos fragmentos en lo alto, inalcanzables para la codicia de los buscadores de reliquias, pero adorables al quedar a la vista de los fieles. Para continuar:

... en nuestros tiempos no había descubierto ningún pedazo de las adorables paredes hacia el Santo PILAR, ni en otro puesto; pero que quando se derrivó el ángulo, que había en donde están las Santa Imagen, y la columna, se hallaron debaxo de los adornos interiores, y exteriores, que hemos dicho, las dos antiguas paredes, y para que quede dellas memoria, este sentimiento de la Tradición, se han dexado colocados sus fragmentos en dos concavidades, que a este fin se labraron en el Ara a los lados de la Santa Columna, lo que digo, porque yo mismo fui testigo de ello, y aún en esta ocasión me franquearon un adobe de ellas, que se guardó con sumo consuelo, y veneración ${ }^{45}$.

\section{Más leyenda aún, y aún algunas dudas}

En 1642 la Virgen del Pilar fue declarada patrona de la ciudad de Zaragoza, cobrando una importancia añadida para el orgullo local; en 1678 se convirtió también en la patrona del reino de Aragón. Si en 1456 Calixto III había reconocido la antigüedad y primacía de la iglesia de Santa María del Pilar en su advocación mariana, en 1680 Joseph Félix de Amada Torregrossa había concluido un texto, dedicado a Carlos II y titulado Compendio de los Milagros de Nvestra Señora del Pilar de Zaragoza, primer templo del Mundo... (Zaragoza, herederos de Joaquín Verges, 1680), en el que no solo defendía que la basílica era el primer templo construido en la Cristiandad, sino que tenía que ser eterno por su propia naturaleza, mientras solo hacía referencia retórica a otras tres grandes construcciones: las basílicas de San Pedro de Roma del papa Anacleto, de Santa Anastasia de Constantinopla y del Santo Cenáculo de Jerusalén (pp. 146-147), que se habían salvado de los sacrilegios y la destrucción.

Es posible que en esas mismas fechas también constituyera un testimonio importante para nuestra leyenda el libro Mística Ciudad de Dios, Vida de María (Madrid, Bernardo de Villa-Diego, 1670, III, 7, pp. 1123-1124)4, de la monja concepcionista Sor María de Agreda (1602-1665); pues para ella, la columna había sido traída nada menos que desde la mismísima Jerusalén. El texto había sido redactado ya en 1640, para terminar quemado de inmediato, ser reescrito en 1660 y publicado solo en $1670^{47}$. La Inquisición española lo requisó apenas fue publicado, y solo lo autorizó en 1686; pero la Inquisición romana, sin embargo, hizo que en 1681 se incluyera en el Índice de libros prohibidos, sucediéndose aprobaciones y condenas papales y universitarias hasta 1773 , fecha en que Clemente XIV impuso silencio sobre esta obra48.

Por estas fechas, sobre la falsación de las leyendas locales propia de la Contrarreforma católica - por parte, por ejemplo, de los cardenales Roberto Belarmino y Cesare Baronio, o el reconocimiento del milagro mariano solo como tradición local por parte de Urbano VIII (1631), frente a su consideración como universal en el Breviarium Romanum de Clemente VIII-, y la oposición a los cronicones de Máximo, Flavio Lucio Dextro y Luit- 
prando, un nuevo criterio racionalista e ilustrado comenzaba a poner en duda la leyenda mariana. Fueron testimonio de ello la solicitud a Roma de un rezo con octava, que se rechaza en 1694 por parte de la Congregación de la Rota y en 1704 por basarse en falsos cronicones, pero que fue finalmente aprobado en 1720 por Inocencio XIII. No olvidemos que, por un edicto de 7 de septiembre de 1720, el inquisidor general Diego de Astorga, arzobispo de Toledo, ya había dictado una orden contra varios impresos y especialmente "contra uno de diez hojas con 46 números" titulado Examen de la tradición del Pilar"4, prohibiéndose su difusión so pena de excomunión y multa de 200 ducados.

De hecho, se estaba respondiendo de forma radical al escrito de Pedro Pablo y Francisco Antonio -pseudónimo del real bibliotecario y cofundador de la Real Academia española Juan de Ferreras (1652-1735) - Examen de la tradición del Pilar (1720, panfleto impreso, Madrid, BNE, Ms. 9501, fols. 9-18 y manuscrito, fols. 19-36 vo), y de los algo anteriores, sin pseudónimo, de Juan de Ferreras, tanto su Synopsis histórica chronológica de España (1700-1727), II (Madrid, Francisco de Villadiego, 1702), como la Historia de España, Parte diez y seis, Madrid, s.a. [1727 y 1776]) y su Dissertatio de praedicatione Evangelii in Hispania per S. Apostolum lacobum Zabedaeum, Madrid, 1705 [ejemplar en Madrid, RAH] y s.a., 171350. Bajo el alias se había señalado que "los críticos han reparado en que no ay monumento alguno en los onze primeros siglos cristianos que afiance esto... [siendo Santiago pobre] así que lo más que se puede asegurar verosímilmente es que el Apóstol hizo iglesia la casa o el aposento donde se hospedó siendo él huésped christiano". Además, ponía en duda la existencia de la imagen que la Virgen habría dejado sobre la columna la Virgen, preguntándose si existieron licencias para la edificación de un templo o hubo tolerancia para una columna con una imagen sobre ella, en una ciudad romanizada, o si el culto era público o particular, e interrogándose por las diferentes bulas, tratados y privilegios, autores y censuras, milagros y revelaciones relativos al templo y sus reliquias.

En cualquier caso, además del origen jerosolomitano de la columna y su transporte milagroso,
Sor María de Ágreda añadió que se habría tratado de la segunda visita de la Virgen a Santiago en España, tras una primera mientras se hallaba en Granada, tras desembarcar en Cartagena. Se explayaba en multitud de detalles, pues se trataba de "Doctrina que me dio la Reina del cielo María santísima", como revelaba Sor María, transcribiendo en "primera persona" la revelación de la Virgen: la Capilla "magnifica y engrandece al Altísimo por el favor que hizo a mi siervo Jacobo en Zaragoza y por el templo que allí me edificó antes de mi tránsito y todo lo que de esta maraviIla te he manifestado, y porque aquel templo fue el primero de la ley evangélica y de sumo agrado para la beatísima Trinidad".

\section{La monja merece ser citada por extenso:}

Yo en nombre del Todopoderoso les prometo grandes favores y bendiciones de dulzura y mi verdadera protección y amparo, porque éste ha de ser templo y casa mía y mi propia herencia y posesión. Y en testimonio de esta verdad y promesa quedará aquí esta columna y colocada mi propia imagen, que en este lugar donde edificaréis mi templo perseverará y durará con la santa fe hasta el fin del mundo. Daréis luego principio a esta casa del Señor, y habiéndole hecho este servicio partiréis a Jerusalén, donde mi Hijo santísimo quiere que le ofrezcáis el sacrificio de vuestra vida en el mismo lugar en que dio la suya para la redención humana ${ }^{51}$.

Sor María apelaba también a la autoridad ${ }^{52}$ del Presidente de Tolosa de Francia, Juan Estefano Duranto, y su "Sacratissimam Virginem Mariam Sancto Jacobo in Civitate Casaraugustæ apparuisse, ibique primum Templum Deiparæ ædificatum fuisse, quod vulgo, Nuestra Señora del PILAR, hispanice appellatur...", esto es, de Jean-Étienne Duranti (Durant o Durand, ca. 1534-1589), primer presidente del Parlamento de Toulouse de 1581 a 1589 y autor de un De Ritibus Ecclessiae catholicae libri 3 (Roma, 1591 y París, 1624). En este texto se recogía la primacía mariana de la iglesia del Pilar, fundándose a su vez en el testimonio de la Primera parte de la corónica generale de toda Espana, y especialmente del Reyno de Valencia (Valencia, Pedro Patricio Mey, 1604, p. 135) de Pedro Antonio Beuter (ca. 1490-1554), un autor básico así como la edición anónima de 1542 del texto de la Apparitio b[eatae]. Mariae de Pilari (como Hic continetur quomodo et per 


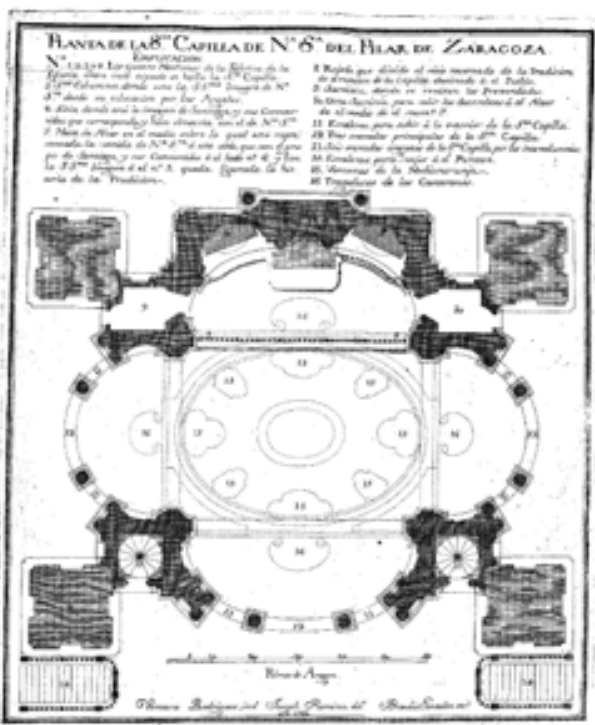

Fig. 7. José Ramírez y Braulio González, Planta de la Santa Capilla de Nuestra Señora del Pilar de Zaragoza, en Vicente Manuel Aramburu, Historia chronológica de la Santa, Angélica y Apostólica Capilla de Nuestra Señora del Pilar de la ciudad de Zaragoza y de los progresos de sus edificaciones..., Imprenta del Rey, Zaragoza, 1766

quos edificata fuit ecclesia beate Marie maioris et de Pilari civitatis Cesarauguste regni Aragonum, ejemplar en Zaragoza, Cortes de Aragón, Biblioteca L 1011 F. Antiguo) ${ }^{53}$. A este texto le había precedido el Flos Sanctorum del fraile jerónimo Pedro de la Vega (Zaragoza, Jorge Cocci, 1541, fol. 448 (Madrid, BNE, R/1568 [R/5168]), con un capítulo "De cómo fue edificada la capilla de nuestra señora santa maría del pilar de la ciudad de Çaragoça de Aragón" y una estampa que mostraba la aparición de la Virgen, con el Niño sobre una alta columna, a Santiago y a sus discípulos.

\section{La Capilla y sus arquitectos antiguos y nuevos}

Todos conocemos el papel de pie forzado no solo de la Capilla del Pilar en su conjunto, sino de la antigua pared de la capilla construida por el mismísimo apóstol Santiago, en el ángulo noroccidental, que a la postre forzaría incluso la posición descentralizada de la imagen mariana y del pilar en la definitiva Capilla de Ventura

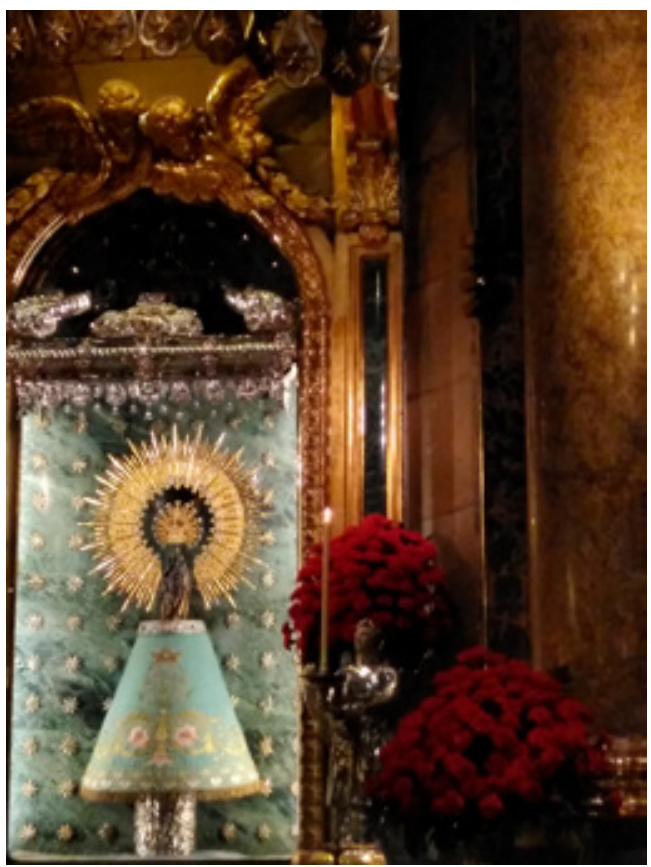

Fig. 8. Virgen del Pilar. Fotografía: Fernando Marías

Rodríguez. Éste mismo, como vimos, lo anotó en la planta de su proyecto fechado en 20 de noviembre de 175054: "6. Pared antigua de la primitiva Sta Capilla edificada por Santiago, que queda reservada en el mazizo de la nueva", e incluso en la maqueta de 1753 señaló el año 56 como fecha de la construcción primigenia55. No obstante, estos datos no pasaron a la posteridad en el grabado de 1766 de José Ramírez y Braulio González, que fue publicado por Vicente Manuel Aramburu (fig. 7) $)^{56}$. La planimetría moderna, de Teodoro Ríos Balaguer (1923/1940), no muestra tampoco esa pared ${ }^{57}$, aunque nos permitiría un control de las medidas de su fábrica de haberse incluido una escala.

Ventura Rodríguez fue nombrado por el rey antes del 7 de septiembre de 1750, el 6 fue visitado por el jesuita José Diego y el 7 salió hacia Zaragoza, donde estaba ya el 15 del mismo mes $^{58}$. Antes de su partida, el jesuita, como refería en carta desde Madrid (del 12 septiembre 1750) a su hermano arquitecto y escultor y también lego jesuita Pablo Diego [Ibáñez] (1676-1751) y quien había intervenido en modelos en $1737^{59}$, le seña- 
laba que había prevenido al arquitecto madrileño de que

... de la primitiva fábrica del Apóstol solo se encontraría un pedazo de muro que hace espaldas a Nuestra Señora de material de adobes, pero sobrenatural, muy fuerte: que esta primitiva y milagrosa fábrica había sido en figura dupla, solo de ocho pies de largo y cuatro de ancho, y que por los años de 500 [por siglo XVI] se había renovado, como conocería por la pared o muralla sostenida de arquitos, que forma la espalda del altar donde se dice misa; por lo que a diferencia de aquel muro de las espaldas de la Santa Imagen que era razón mantenerlo, todo lo demás podía destruirlo, sin hacer mérito de ello para nada, y entre sus cuatro postes, con la diafanidad más extensa que pudiera, [que] echase sus líneas para la nueva planta, y sobre todo a la parte que mira la Santa Imagen dejase la vista de su rostro a los fieles ya [que] pues así la dejó el Apóstol, mirando a la puerta por donde se entraba en aquel reducido templo ${ }^{60}$.

En el muro oeste de la Capilla se abre un pequeño orificio —el "humilladero" (figs. 2 y 3)— que permite ver y besar lo que los fieles pensarían que debería ser la columna mariana, pero que hacia esas fechas todavía debería de haber sido más propiamente la pared construida por Santiago, de la misma forma que aparece en el dibujo de Rodríguez con la "Elevación exterior [...] mirada por la parte de la adoración del Santo Pilar" de la parte occidental de la Capilla, conservada en el Archivo del Pilar, señalado así: "Por el Hueco $A$ se adora el Santo Pilar" ${ }^{61}$. En el dibujo de la planta se distingue una ligera discontinuidad en la citada pared apostólica, perfectamente delimitada, que definiría su moderno horadamiento (fig. 1). Los orificios abiertos en las envolturas del Pilar, que dibujó Julián Yarza en 1756 (fig. 4), permitían tocar y besar —o a la bizantina proceder a su proskínima, a través del humilladero- el núcleo pétreo de la columna, pero no sabemos desde cuándo ni desde dónde, si directa y frontalmente o a través de una pared de fábrica, fuera la original legendaria o la medieval.

Los planos del siglo XVII dan importantes pistas. En el de 1668, o quizá ahora de 1610/161762, que daba testimonio de la situación medieval y quinientista, el Pilar se contemplaba directamente desde el exterior del recinto, por lo que la colum- na se vería a través de los sucesivos orificios abiertos en la primera envoltura, de plomo, de las dos con la que la protegieron; en un diseño anónimo, recientemente descubierto, un muro ocultaría la columna ${ }^{63}$. Muy próximo a esta imagen sería el esbozo de Juan Bautista Labaña, en su Itinerario del Reino de Aragón, de 1610-161164 en el que se mostraba la Cámara angélica, donde se encontraba la reliquia, como una capilla solo para el clero y personas reales, y que se correspondería con la construcción primitiva de Santiago, quedando el espacio público más allá de la cancela.

En el dibujo de Felipe Sánchez fechado hacia 1679, con disposición de los soportes de la basílica en ritmo continuo, parecería encontrase la columna entre la pared occidental de la antigua capilla y el altar, quizá como testimonio de su ubicación tradicional. En el proyecto que hemos atribuido a Herrera el Mozo parece vislumbrarse una nueva situación del altar en la pared norte y que la columna se lograba contemplar por medio de un nuevo agujero horadado en la pared occidental65; es probable que, sin girar la columna, se hubiera derribado la pared preexistente, erigiendo una nueva al oeste de ella y abierto el orificio para poder rendirle una especial devoción desde Poniente. En el diseño de la cimentación de Sánchez, se había colocado nuevamente el altar en la pared norte, y la columna se alcanzaba a ver a través de un orificio abierto en la pared occidental. En el siglo XVIII, finalmente se colocaron por parte de Ventura Rodríguez tanto el altar como la columna en el lado de Poniente, abriendo de forma definitiva el previsto orificio en la nueva basílica del siglo XVII, tal como se podría constatar en el polícromo dibujo de las décadas de 1720 o 1730, con el altar a occidente y, por encima, la columna, que habría de tocarse desde Poniente, aunque ya en el informe de 1548 se plantearan serias dudas.

Es muy probable que en este punto hubieran estado de acuerdo todos los individuos y colectivos que sucesivamente intervinieron de alguna forma en la toma de iniciativas y decisiones entre 1675 y 1750 . No solo se defendía la reliquia del Pilar, donde la Virgen había plantado sus pies, sino la construcción que un Santiago apóstol, y maestro de obras si no arquitecto, había erigido en su honor, haciendo de esta fábrica no solo la 
primera iglesia construida en toda la Cristiandad, y además dedicada a María, sino además levantada por un apóstol, cuyos restos han sido, sin embargo, si no destruidos al menos ocultados y olvidados ${ }^{66}$. Con ella Zaragoza se habría adelantado nada menos que a la basílica romana de Santa Maria Maggiore, que había sido fundada por el papa Liberio después del año 360, tras una aparición de la Virgen, y había sido reconstruida por Sixto III (432-440) después de afirmarse el dogma de la maternidad divina en el Concilio de Éfeso (431), y que además estaba bajo un tradicional patronato hispano ${ }^{67}$. Toda una leyenda.

\section{Razones para un olvido y una propuesta}

Como se ha visto hasta ahora, los restos de la Capilla que habría construido el apóstol Santiago han sido, si no destruidos del todo, al menos ocultados y olvidados, también por la historiografía. La pregunta sobre las causas de este olvido sigue aún sin respuesta, aunque a estas alturas de la investigación podamos sospechar que se debió a una de dos probabilidades, o a las dos a la par pues son perfectamente complementarias: por un lado, debido a la conocida competencia que la sede arzobispal zaragozana mantenía con otras sedes hispánicas como Toledo, Tarragona o Santiago de Compostela; por otro lado, por la durísima competencia que por cuestiones de preeminencia, ceremonial y honores se daba en la propia Zaragoza desde el siglo XIII entre el cabildo de la basílica Pilar y el cabildo de la Seo de San Salvador, que reclamaba su preferencia por estar ubicada en su templo la cátedra episcopal.

Por resumir, el cabildo de la basílica fomentó el culto del Pilar en paralelo al culto toledano y de Santiago apóstol en paralelo al culto compostelano. A la par, la leyenda de la construcción de la primitiva capilla apostólica recibió impulso a partir del reinado de Felipe III, a la vez que se reforzaba el culto jacobeo frente a la propuesta de hacer de Teresa de Jesús la patrona nacional, se acrecentaba la importancia concedida a la descensión de la Virgen en la catedral de Toledo y se reforzaba su culto gracias a los descubrimientos granadinos del Sacromonte de Valparaíso y los libros plúmbeos, y todo ello en un momento de gran fervor inmaculadista, como hemos visto hasta ahora. Las fábulas de carácter mitológico y civil, las tradiciones hagiográficas, los milagros y las reliquias fueron así instrumentos del poder político tanto como del orgullo local, y sobre todo a partir de 1642, cuando la Virgen del Pilar fue declarada patrona de la ciudad de Zaragoza. La pregunta es por qué después solo pasó a defenderse la historia de la reliquia del Pilar, donde la Virgen habría plantado sus pies, y no aquélla sobre la construcción de la capilla por parte de un Santiago apóstol que, metido a maestro de obras si no también arquitecto, habría erigido la primera iglesia construida en toda la Cristiandad y la primera consagrada a la Virgen.

Es más que probable que, tanto en un caso de competencia entre sedes hispánicas o entre sedes locales, el cabildo del Pilar considerara mejor dar prioridad a la reliquia del Pilar más que a la reliquia de la capilla de Santiago por una mera cuestión de precedencia entre reliquias, de modo que, a la par, pudiera subrayarse así la preferencia entre sedes episcopales tanto a nivel de la Iglesia hispánica como a nivel local; a la postre, el cabildo del Pilar podía presumir de tener una reliquia de primer orden de un modo que no podían hacerlo ni otras sedes episcopales ni el cabildo de la Seo zaragozana. A nivel local, el conflicto debería haber quedado resuelto con la llamada Bula de Unión, promulgada por el papa Clemente $X$ el 2 de febrero de 1675 y confirmada por Inocencio $\mathrm{XI}$ el 16 de octubre del año siguiente, pero las disputas debieron de continuar subrepticiamente durante el siglo siguiente. No tenemos muchas dudas sobre el hecho de que la desaparición o, al menos, el ocultamiento de la última pared superviviente de la capilla construida por Santiago haya de ser enmarcada en este contexto de confrontación y poder, más político que celestial.

A estas circunstancias habría que sumar las preguntas que en ocasiones se vertieron tanto contra la venida de Santiago a España como contra la propia venida de la Virgen para animarlo en su tarea de evangelización. Aunque hemos anticipado algunas ya, convendría detenerse ahora en publicaciones tan relevantes como prolijas como el célebre Compendio de los milagros de Nuestra Señora del Pilar de Zaragoça que Amada y Torregrosa publicó en 168068; a otras publicaciones mucho menos conocidas como una Carta que un José de Villanueva escribió contra las 
incertidumbres de un anónimo — que ya hemos citado por debajo de su pseudónimo-y publicó en fecha tan avanzada para nuestro asunto como es $1723^{69}$. Parece que tanto una como otra, a las que se podrían añadir otras citadas en este ensayo, forman parte de eso que Alexander Nagel y Christopher Wood han Ilamado, en su Anachronic Renaissance, una hypertrophy of explanation ${ }^{70}$, refiriéndose a la Santa Casa de Loreto que tantas concomitancias podría tener con nuestra capilla del Pilar al menos en algún sentido. Son, de hecho, algunas de esas concomitancias entre Loreto y el Pilar las que podrían contribuir no tanto a la consecución habitual de una historia tipológica de las reliquias, sino más bien a lo que nos atreveríamos a llamar una historia morfológica de las reliquias, una historia en la que la materialidad de las mismas no tendría solo relevancia para entender la devoción que se les profesara, sino también para construir eso que acabamos de llamar historia morfológica, en la que tanto el sentido de la vista71, como el sentido del tacto, menos analizado aún pero igual o más importante que la vista como se apreciará al final de este texto, desempeñarían un papel esencial, y en la que las similitudes, pero también las diferencias entre los distintos casos, desempeñarían una función de primer orden.

En cualquier caso, ahora interesa volver al hecho de que las dimensiones de la capilla original, que tanto preocupaban al jesuita José Diego tal y como revela la carta a su hermano y según habría expuesto a Ventura Rodríguez en aquella noche de urgencias a la que nos referíamos antes, como la fortaleza sobrenatural de los muros que, a pesar de estar hechos de un material tan modesto como el adobe, habían perdurado durante siglos, fortaleza que era también prueba de su autenticidad, así como el material del que estaba hecho el pilar sobre el que viajó y se aposentó la Virgen, con sus respectivas connotaciones simbólicas, formarían parte de una argumentación que podríamos denominar estructural, y que domina no solo el relato informal del jesuita, sino otros más oficiales sobre la reliquia del Pilar y, también, sobre la capilla que a su alrededor construyó el apóstol Santiago por mandato de la Virgen. De hecho, el tamaño y la materialidad de la capilla primitiva construida por los ángeles, Santiago y sus compañeros de travesía eran componentes esenciales de la reverencia, el respecto y la devoción que, según el jesuita José Diego, se debía a los vestigios de los que, no por casualidad, parecía tener una experiencia de primera mano. Indudablemente, para el jesuita, que recordemos salió de su casa nada más enterarse de que Ventura Rodríguez había sido nombrado arquitecto de la fábrica del Pilar a última hora de un día de septiembre para ponerle al tanto de lo que se encontraría allí, lo más relevante era mantener los muros por su autenticidad y, a la par, que las nuevas obras capitaneadas por Ventura Rodríguez acabaran con bien. Autenticidad y ornamentación ${ }^{72}$, por tanto, en una solo aparente contradicción que es muy frecuente en la recepción de los objetos de culto, o mejor dicho en nuestro caso, autenticidad y arquitectura: los lugares de devoción y su trascendencia como marco para la exposición y devoción de las reliquias y, con ellas, para la construcción de diversas identidades o también para desarrollar nuestros análisis hoy.

Para Nagel y Wood la contradicción aparente entre autenticidad y ornamentación habitualmente se resolvía diferenciando reliquia y relicario y asignando diferentes funciones a cada una de las partes. Sin embargo, en otros casos, como el de la Casa de Loreto y sus distintas versiones, arquitectura y objeto de culto convergen y son una y la misma cosa, con todo lo que ello supone. Por el contrario, en el caso de la capilla del Pilar de Zaragoza la partida la ganó la "reliquia-reliquia", es decir el Pilar, y no el modesto pero "santo" edificio que la contenía, o sea la capilla que, según la tradición, había sido construida por Santiago. Las razones para que esto resultara así nada tuvieron que ver con la devoción. Esas razones eran razones de cardinal importancia: para una historia morfológica de las reliquias, el problema fundamental.

\section{Corolario}

Para finalizar, si pensamos en el olvido de la casa-iglesia de Santiago, tendríamos que plantearnos también el tema de la historicidad de la reliquia material del pilar zaragozano. Nada sabemos, en realidad, sobre la naturaleza de la columna original, como tampoco respecto a la imagen mariana de madera, atribuida por María del Carmen Lacarra Ducay tal vez al escultor Juan/ 


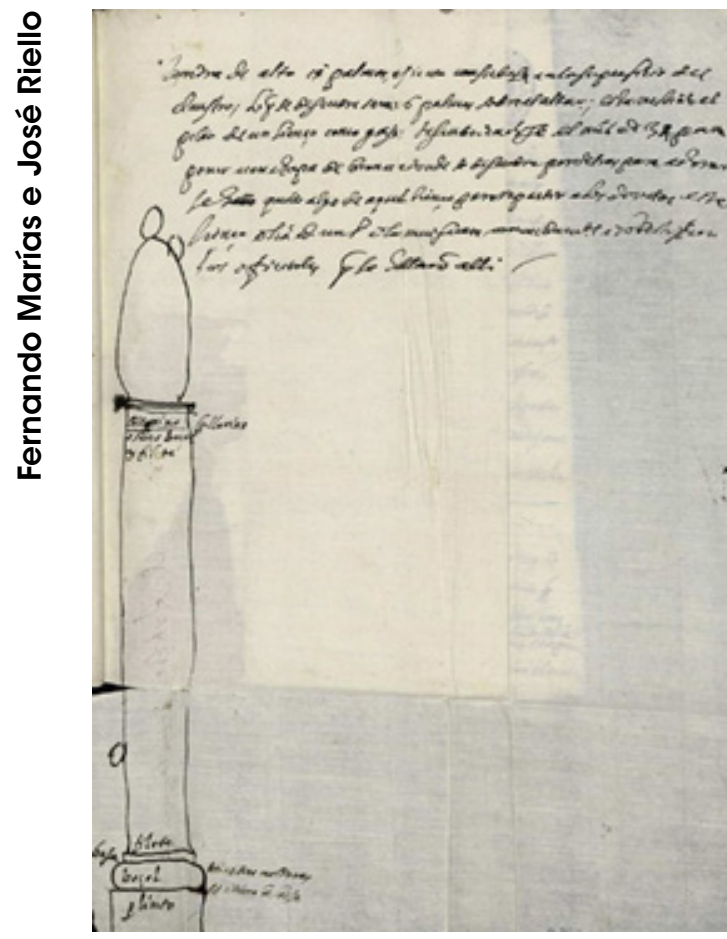

Fig. 9. Fray Jerónimo de San José, "Historia de Nuestra Señora del Pilar de Çaragoza", Zaragoza, 1647, Madrid, Biblioteca Nacional de España, Ms. 7224, fol. 3

Jean de la Huerta y fechándola a fines del siglo $\mathrm{XV}$. Parece haber noticias de una imagen desde 1456 y de su situación sobre la columna desde al menos $1542^{73}$.

Oficialmente, la columna habría estado presente desde la primitiva iglesia jacobea, y después en las sucesivas construcciones: el templo edificado por san Braulio en el siglo VII, aunque nada aparece en sus textos ${ }^{74}$, del que se conservan restos de un cancel visigótico o mozárabe ${ }^{75}$; el templo románico impulsado por el rey Alfonso el Batallador y el obispo Pedro de Librana; la iglesia gótica que se comienza a construir a finales del siglo XIII y se concluye en el XVl; y la actual, el templo barroco, con la Santa Capilla de Ventura Rodríguez concluida en 1765. Una cosa parecería clara: "Todas estas edificaciones han conservado la sagrada Columna como centro de devoción, sin modificar su ubicación. Besar el Pilar es pisar el punto exacto en el que se encontraron María, la Virgen, y Santiago, el apóstol"76.
“ ¿Pero cómo es la Columna? — se nos insiste- - Un fuste cilíndrico de jaspe de una altura de 10 palmos y 2 dedos, con una proporción de 8 diámetros, aunque es ligeramente más estrecho en la parte superior". En resumen 1,77 metros de altura y 24 centímetros de diámetro. Lo que vemos es de un color que oscila del amarillo al rojo, con algunas vetas violáceas [aunque en 1548 se señalara que era de piedra blanca, añadiríamos nosotros ahora, como veremos de inmediato]. Una columna, como las que Roma y sus colonias utilizaban en sus mejores construcciones" 77 .

¿Qué medidas tenía y tiene? ¿Cuál era y es su forma? ¿De qué piedra estaba hecha? ¿Pórfido, jaspe de Tortosa, piedra blanca? Da la impresión de que sorprendentemente desde mediados del siglo XVI, nadie la ha visto y, por consiguiente, nadie puede juzgarla (fig. 8).

En 1548, el encargado de vestir la imagen de la Virgen del Pilar refirió al arzobispo de Zaragoza Fray Hernando de Aragón, a través del abad de Veruela Fray Lope de Marco, que

... De verdad el Pilar está guarnesçido de una hoja de yerro y que es de una piedra blanca lo que se mostrava dél a canto del altar a que está arrimado y que el pedazo del mármol del jaspe que la gente por la claustra de fuera llega a tocar, que no llega alli el de dentro sobre donde nuestra señora, que la figura de nuestra señora es de bulto de madera y de piedra mármol blanco assentada en el Pilar que es piedra común $n^{78}$.

Según este testimonio olvidado, el pilar era de piedra blanca79, y el jaspe que se tocaba jno podía ser alcanzado desde el volumen real de la columna por las manos de los fieles!

De enorme interés es el manuscrito del carmelita descalzo Fray Jerónimo de San José (15871654), amigo de Juan Francisco Andrés de Ustarroz, "Historia de Nuestra Señora del Pilar de Çaragoza", donde diseña una imagen muy aproximativa de la columna y la imagen de la Virgen (fig. 9), señalando el hueco del humilladero, dando unas medidas y señalando sus diferentes partes: "collarino / collarino, ésto es boçel y filete [del sumóscapo del fuste]/ filete [del imóscapo del fuste] / basa [a la manera de una basa toscana] / boçel / plinto" 80. 


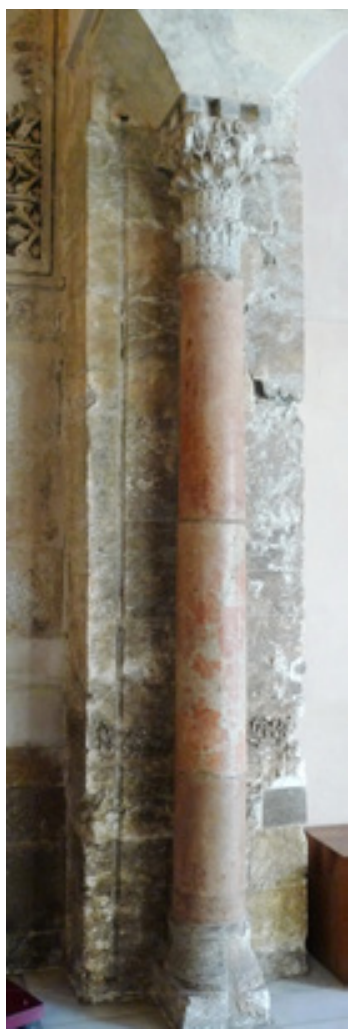

Fig. 10. Palacio de la Aljafería, Zaragoza. Fotografía: Fernando Marías

Por su parte, Fray Joseph Antonio de Hebrera en 1719 (pp. 9-12) señalaba que era de jaspe y de una altura de poco más de dos varas (unos $175 \mathrm{~cm}$ ), y otras fuentes del siglo XVIII sostenían genéricamente que era de mármol.

Ninguna de las representaciones medievales, modernas o contemporáneas de la columna, que parecen imaginarias a partir del tipo de columna más usual en el medio para cada una de las épocas ${ }^{81}$, parecen encajar con las informaciones proporcionadas por un dibujo de Julián Yarza (fig. 4), quien parecería haber sido de los pocos que llegaran a verla en su integridad, aunque no es seguro que sin sus revestimientos de plomo y plata, sobre los que volveremos de inmediato. Yarza señalaba diferentes partes del pilar: A-H alto de la Santa Columna de más de 10 palmos (unos $206 \mathrm{~cm}$, tanto sin la basa F "que estaba" o G "como ha quedado"), medida que no coincide con lo que se viene dando modernamente, es decir 170/178 x $24 \mathrm{~cm}$ de diámetro, para la columna de jaspe rosado o brocatel de Tortosa.

Los problemas se derivan, en primer lugar, de que es difícilmente visible a causa de los dos revestimientos que recubren la columna (fig. 8); el primero, metálico o de plomo (s. XV-XVI, citado ya en 1542, aunque en 1616 ya se describa como de plomo); el segundo, de plata labrada, de $1718^{82}$ o de 1739.

Si volvemos al dibujo dieciochesco, se señalaba claramente que la columna estaba formada por tres fragmentos superpuestos de un fuste $(A B, B C$ y $\mathrm{CH}$ ). Da, así pues, la impresión de que la columna era en realidad desde época medieval un conglomerado de piezas varias, que tenían que mantenerse gracias al envoltorio metálico que preservaba su forma columnaria. Pero, ¿cuál era exactamente ésta? ¿Cuál era su perfil, su ságoma? ¿Tenía un éntasis propio de las columnas romanas? Nuestro dibujo, y otros posteriores, le procuran un éntasis de columna clásica, pero ello no es muy creíble si pensamos en la faja estrictamente cilíndrica de sus dos envoltorios protectores. Habría que pensar más bien en un soporte originalmente cilíndrico, alejado de los testimonios arqueológicos de la Cesaraugusta romana ${ }^{83}$. Y ello nos llevaría a aproximarla a soportes quizá de época taifal, columnas y capiteles musulmanes del siglo XI, también hallados en las excavaciones de la basílica ${ }^{84}$. Nada habría sido más lógico que reutilizar, como expolio, una columna de la religión conquistada, similar a las que hoy todavía podemos ver en la Aljafería zaragozana (fig. 10). Pero esta hipótesis podría ser otra leyenda.

No obstante, lo crucial es también que la reliquia hoy olvidada y la muy presente constituyeron objetos y valores que cumplían, por decirlo con Hobsbawm y Ranger ${ }^{85}$, los tres tipos de tradiciones, aun inventadas, que solían interponerse en tal casos: aquéllas que establecían y simbolizaban la cohesión social o la pertenencia a un grupo, fueran comunidades reales o artificiales; las que establecían o legitimaban instituciones, estatus o relaciones de autoridad y competencia; y, por último, las que tenían como primer objetivo la socialización, inculcar creencias, sistemas de valores o convenciones relacionadas con el comportamiento de una sociedad determinada. En ello, el Pilar de Zaragoza se lleva la palma. 


\section{NOTAS}

1 Este trabajo se ha realizado en el marco del Proyecto de investigación "Hacia Antonio Acisclo Palomino. Teoría e historiografía artística del Siglo de Oro", HAR2016-79442-P del Ministerio de Ciencia e Innovación (MICINN). Constituye una versión muy ampliada de nuestra comunicación "Vestir u ocultar la arquitectura: de Santiago apóstol como arquitecto a Ventura Rodríguez", presentada a la Mesa 1: Texturas. La piel de la arquitectura del XXII CEHA Burgos 'Vestir la arquitectura', celebrado entre el 19 y el 22 de junio de 2018, Burgos, Universidad de Burgos (en prensa). También nuestras hipótesis fueron presentadas en el $V$ Seminario Internacional Arte y Cultura en la Corte: Redes artísticas, circulación y exposición de reliquias en el Mundo Hispánico, Madrid, Universidad Autónoma de Madrid-IULCE, del 24 al 26 de abril de 2019, en nuestras respectivas ponencias "Aceptar creencias, verificar historias, falsar reliquias: el caso de la columna de la Virgen del Pilar" y "Cuando conviene olvidar reliquias: el apóstol Santiago en la Capilla del Pilar de Zaragoza".

2 R. L. Kagan (y colaboración de F. Marías), Imágenes urbanas del mundo hispánico 1493-1780, El Viso, Madrid, 1998 y Urban Images of the Hispanic World, 1493-1793, Yale University Press, New Haven-Londres, 2000.

3 W. Rincón, "Tres vistas de Zaragoza del siglo XVII", en Velázquez y el arte de su tiempo, Alpuerto, Madrid, 1991, pp. 299-308.

4 M. Barrios Aguilera y M. García-Arenal (eds.), Los plomos del Sacromonte: invención y tesoro, Valencia, Universidad de Valencia, 2006; M. García-Arenal y F. Rodríguez Mediano (eds.), La ¿Historia inventada? Los Libros plúmbeos y el legado sacromontano, Universidad de Granada, Granada, 2008; M. García-Arenal y F. Rodríguez Mediano, The Orient in Spain. Converted Muslims, The Forged Lead Books of Granada, and the Rise of Orientalism, Brill, Leiden-Boston, 2013 (ed. ampliada de su Un Oriente español. Los moriscos y el Sacromonte en tiempos de Contrarreforma, Marcial Pons, Madrid, 2010), pp. 202-204. También D. Coleman, Creating
Christian Granada: Society and Religious Culture in an Old-World Frontier City, 1492-1600, Cornell University Press, Ithaca-Londres, 2003; A. K. Harris, From Muslim to Christian Granada: Inventing a City's Past in Early Modern Spain, Johns Hopkins University Press, Baltimore, 2007; F. J. Martínez Medina, Cristianos y musulmanes en la Andalucía moderna. La Granada del siglo XVI, una ciudad intercultural: Invenciones de reliquias $y$ libros plúmbeos, Tesis doctoral, Universidad de Granada, Granada, 2015, pp. 58-60.

5 B. Ortiz, Summi Templi Toletani [perquem graphica] descriptio, Juan de Ayala, Toledo, 1549, donde se presenta la piedra como scabellum e inscripción; R. Gonzálvez y F. Pereda, La catedral de Toledo 1549. Según el Doctor Blas Ortiz Descripción gráphica y elegantísima de la S.I. de Toledo, Antonio Pareja Editor, Toledo, 1999; F. J. Aranda Pérez, "De invenciones, controversias y polémicas historiográficas y políticas en la Monarquía Hispánica en tiempos de Quevedo (y aún un siglo después)" , La Perinola, 18, 2014, pp. 15-61; también F. Marías, "Pintura, diplomacia y censura en la Cappella Paolina: desde Toledo y Madrid hasta Roma" [2011], en I rapporti tra Roma e Madrid nei secoli XVI e XVII: arte diplomazia e politica, ed. A. Anselmi, Gangemi, Roma, 2015, pp. 58-86.

6 Historia de rebus Hispaniae, Toledo, 1592; Historia general de España, Toledo, 1601; Madrid, 1608; Madrid, 1617; Madrid, 1623; Madrid, 1650.

7 E. K. Rowe, Disrupting the Republic: Santiago, Teresa de Jesus, and the Battle for the Soul of Spain, 16171630, Ph.D. diss., The Johns Hopkins University, Baltimore, 2005 y Saint and Nation. Santiago, Teresa de Jesus, and Plural Identities in Early Modern Spain, University Park, The Pennsylvania University Press, 2011, pp. 20-46. También K. E. van Liere, "The Missionary and the Moorslayer: James the Apostle in Spanish Historiography from Isidore of Seville to Ambrosio de Morales", Viator, 37, 2006, pp. 519-543; O. Rey Castelao, "Teresa, patrona de España", Hispania Sacra, 67, 136, 2015, pp. 531-573.

848 x $68 \mathrm{~cm}$, Zaragoza, 20 de noviembre de 1750, en Archivo del Cabildo Metropolitano de Zaragoza, sin signatu- ra. No aparece en los dos dibujos de la Capilla en las Plantas generales de la basílica del Archivo del Pilar, 22_1; tampoco en los diseños del Museo de la Real Academia de San Fernando de Madrid, A-4413 y A-4415.

9 S. Arbaiza Blanco-Soler y C. Heras Casas, "Legado de D. Silvestre Pérez a la Real Academia de San Fernando (Exposición Enero-Abril 1994)", Academia, 79, 1994, pp. 341-386: A-4407, A-441 (cripta), A-4409, A-4408, A-4410 y A-5775(a), A-4414, A-5101 (alzado occidental), A-4415, A-5116. También, para la basílica: A-4413, A-4412(a), A5775(b). C. Heras Casas y S. Arbaiza Blanco-Soler, "Inventario de los dibujos arquitectónicos (de los siglos XVIII y XIX) en el Museo de la Real Academia de las Bellas Artes de San Fernando", Academia, 91, 2000, pp. 79-238 y 9293, 2001, pp. 103-271. Véase, ahora, J. Ortega Vidal, J. L. Sancho Gaspar y F. J. Marín Perellón, Ventura Rodríguez. El poder del dibujo, Comunidad de Madrid, Madrid, 2018, n. ${ }^{\circ} 11$, pp. 136-151.

10 O. Hycka Espinosa, Santa María La Mayor y del Pilar de Zaragoza, evolución histórica del templo colegial, Institución Fernando el Católico, Zaragoza, 2018, pp. 166-168; sobre el adoratorio, pp. 188-189y, en general, sobre la CapiIla, pp. 147-193. Véase sobre este tema la sección final de este artículo.

11 A. M. ${ }^{a}$ Muñoz Sancho, "Aportación documental al proceso de ejecución del ornato escultórico de la Santa Capilla del Pilar de (1757-1768)", Artigrama, 29, 2014, pp. 385-412; B. Boloqui Larraya, "Escultura zaragozana en la época de los Ramírez, 1710-1780", Ministerio de Cultura, Granada, 1984; A. Ansón y B. Boloqui, La Santa Capilla del Pilar, CAl, Zaragoza, 1998.

12 Sobre éste, J. Martínez Molina, "La llustración, una edad de oro de la arquitectura aragonesa (1750-1808)", en D. J. Buesa Conde (ed.), Pasión por la libertad. La Zaragoza de los Pignatelli, Ibercaja, Zaragoza, 2016, pp. 314-355, esp. 321-322. Señala que, en 17711772, presentó una propuesta fallida para ejecutar los adornos de estuco del Coreto del Pilar, ejecutando, sin embargo, el ornamento de uno de sus óculos, el facistol del Coreto y la caja de su órgano. No obstante, la fecha del dibujo 
plantea dudas al respecto de esta afirmación.

13 Director de los estudios de la Academia de San Fernando en Zaragoza, fue nombrado individuo de mérito de arquitectura el 7 de agosto de 1774 . Véase T. Ríos Balaguer, "Algunos datos para la historia de las obras del actual Santo Templo Metropolitano de Nuestra Señora del Pilar de Zaragoza", Boletín del Museo provincial de Bellas Artes, ix, 11, 1925, pp. 1-48 y 12, 1926, pp. 4979 , doc. 30, p. 79.

14 La idea de un Santiago arquitecto - frente a la tradición de un santo Tomás arquitecto (según los "Hechos de Tomás", un apócrifo del siglo III) - solo podría haber encontrado justificación textual a partir de su supuesta hermandad con Jesús (según otras fuentes éste habría sido Santiago el Justo o Santiago Alfeo, obispo de Jerusalén); dado que éste (Marcos 6, 3) habría sido carpintero, o hijo de un carpintero (téchton, en griego) o constructor/maestro de obras como José (Mateo 13, 55), habría sido lógico que su hermano se formara también en este oficio. Como Díaz de Ribas escribía en sus De las antigüedades y excelencias de Córdoua, Córdoba, 1627, en la iglesia de la Jerusalén Santa fundada por el apóstol Santiago se habría seguido el modelo del Templo de Jerusalén.

15 Más que del hispalense Isidoro de Sevilla (h. 556-636) de hacia 620, al que también se le atribuyó este texto para remontarlo más en el tiempo.

16 M. C. Díaz y Díaz, Estudios jacobeos, Universidad de Santiago, Santiago de Compostela, 2010, pero véase también R. McNally, "Christus in the pseudo-isidorian Liber de ortu et obitu patriarcharum", Traditio, 21, 1965 pp. 167-183 e "Isidoriana", Theological Studies, 20, 1959, pp. 432-442, y la edición de C. Chaparro Gómez, París, Les Belles Lettres, 1985.

Para Zaragoza, véase desde $\mathrm{F}$. Fita, "El Pilar de Zaragoza. Su templo y su tradición histórica hasta el año 1324", Boletín de la Real Academia de la Historia, 44, 6, 1904, p. 525, a A. Isabel Magallón y J. C. Martín, "La leyenda de la venida de la Virgen a Zaragoza (BHL 5388): edición crítica y estudio", Hagiographica. Rivista di agiografia e biografia della Societá Internazionale per lo Studio del Medioevo Latino, xxi, 2014, pp. 53-84.

17 Ya se tratara de una defensa de Mauregato como rey, como de la religión católica de los godos romanos frente a los adopcionistas nestorianos del Toledo de Elipando, o un refuerzo de las primeras décadas de la "reconquista" frente al Islam de al-Ándalus. Véase F. Márquez Villanueva, Santiago: trayectoria de un mito, Bellaterra, Barcelona, 2004, pp. 35-77, quien omite cualquier referencia a Zaragoza. O. Rey Castelao, Historiografía del voto de Santiago: recopilación crítica de una polémica histórica, Universidad de Santiago, Santiago de Compostela, 1985 y LoS mitos del apóstol Santiago, Nigra Trea, Vigo, 2006. También, en general, L. Cardaillac, Santiago Apóstol. El santo de los dos mundos, El Colegio de Jalisco, Guadalajara, 2002 y Santiago aquí, allá y acullá. Miscelánea de estudios jacobeos, El Colegio de Jalisco, Guadalajara, 2004.

18 Véase ahora F. J. Martínez Medina, Cristianos y musulmanes en la Andalucía moderna. La Granada del siglo XVI, una ciudad intercultural: Invenciones de reliquias y libros plúmbeos, Tesis doctoral, Universidad de Granada, Granada, 2015, pp. 58-60.

19 Los Varones apostólicos lo habrían acompañado en su evangelización hispana para después regresar para trasladar el cuerpo del apóstol martirizado hacia 44. M. Sotomayor y Muro, "La Iglesia en la España romana: Antiguas tradiciones sobre los orígenes del cristianismo hispana", en Historia de la Iglesia en España. I: La Iglesia en la España romana y visigoda (siglos I-VIII), ed. R. García Villoslada, Biblioteca de Autores Cristianos, Madrid, 1979, pp. 149-165; L. A. García Moreno, "La monarquía visigoda y la Iglesia en Levante: las raíces de un país", Alebus: Cuadernos de Estudios Históricos del Valle de Elda, 6, $1996, \mathrm{pp}$. 7-30; L. A. García Moreno, "Santiago y los varones apostólicos en la España altomedieval: ¿enfrentados o complementarios?", en A. Sánchez Ribes (ed.), El mediterráneo en el origen. IX Congreso Internacional de Asociaciones Jacobeas, Asociación Amigos del Camino de Santiago de la Comunidad Valenciana, Valencia, 2012, pp. 15-26.
20 Los restos encontrados en 1879 solo fueron "autentificados" por la Iglesia en 1884, bajo el pontificado de León XIII.

21 Conocido como Apparitio b. Mariae de Pilari (con el título "Qualiter hedificata fuit basilica sancte Marie de Pilarii Cesarauguste. Rubrica"), del códice de las "Moralia in Job" (578-595) de San Gregorio Magno, de finales del siglo XIII o comienzos del XIV (copiado por un tal Pedro Poncas de Roncal, de perfiles imprecisables), hoy custodiado en el Archivo Pilarista (I, fols. 274va-275rb); su primera impresión fue como Hic continetur quomodo et per quos edificata fuit ecclesia beate Marie maioris et de Pilari ciuitatis Cesarauguste regni Aragonum, Diego Hernández (?), Zaragoza, 1542, a partir de un manuscrito hoy desaparecido.

22 En su Libellus diversi carminis metro, con los poemas de las iglesias de santos de Zaragoza. Véase Eugenii Toletani Opera Omnia, ed. P. Farmhouse Alberto, Brepols, Turnhout, 2005, y antes otras ediciones desde la moderna de F. K. Vollmer, "Eugenii Toletani episcopi carmina", en Monumenta Germaniae Historica, Auctores antiquissimi 14, Fl. Merobaudis reliquiae, Blossi Aemilii Dracontii carmina, Eugenii Toletani episcopi carmina et epistulae, Berlín, 1915, pp. 229-291, especialmente pp. 239-241, Carmen (VII) IX, (VIII) X y (X) XI.

${ }^{23}$ Sobre los orígenes $y$ testimonios - y las causas de su pérdida- del evento milagroso, M. V. Aramburu, Historia chronológica de la Santa, Angélica y Apostólica Capilla de Nuestra Señora del Pilar de la ciudad de Zaragoza y de los progresos de sus edificaciones..., Imprenta del Rey, Zaragoza, 1766, pp. 15-36.

${ }^{24}$ Hoy comentado por X. Gil Pujol, "El pastelero anticuario. Luis López y sus obras de Zaragoza en los años 1630 y 1640", en F. Andrés Robres, M. Hernández Benítez y S. Martínez Bermejo (eds.), Mirando desde el puente. Estudios en homenaje al Profesor James S. Amelang, Universidad Autónoma, Madrid, 2019, pp. 71-81.

25 Según el monje benedictino franco Aimoino de Saint-Germain-dePrés ([Aimond de Bernon], †ca. 897) de París, sobre un relato de Audaldo, quien 
habría pasado por Zaragoza en el 855 con los restos de san Vicente Mártir, de quien habría redactado en 870/888 una Historia translationis S. Vicentii levitae et mart. ex Hispania ad Castrense in Gallia monasterium: auctore Aimonio monacho ord. S. Benedicti, Imprenta Real, Madrid, 1806, lectio V, p. 177 (y en Viaje Literario a las iglesias de España, ed. J. Lorenzo Villanueva, Imprenta de Fortanet-Real Academia de la Historia, Madrid, 1806, IV, pp. 167-209), Audaldo le habría citado una iglesia de la Virgen María como matrem ecclesiam de Zaragoza.

De fines del siglo $X$ dataría una referencia a dos iglesias de Zaragoza: Santa María y Santas Masas (más tarde basílica del Pilar y monasterio de Santa Engracia, respectivamente), a las que dejó mandas de cien suelos el cristiano barcelonés Moción (hijo de Fruya, apresado por Almanzor en 985, fallecido en Zaragoza tras su liberación en 986, y en cuyo testamento de 987, otorgado en Vallvidriera, había donado 100 soldadas a Santa María intramuros de Zaragoza). Ambos datos en Z. García Villada SI, Historia eclesiástica de España, I, 1. ${ }^{\text {a }}$ parte, Compañía Ibero-Americana de Publicaciones, Madrid, 1929, pp. 103 y 71. También J. Alturo i Perucho, "El testamento sacramental de Moción del año 987 y su redactor, el juez Ervigio Marco", en R. Marín López (ed.), Homenaje al Prof. Dr. José Ignacio Fernández de Viana y Vieites, Granada, 2012, pp. 2944. Agradecemos estas precisiones a la Prof. María Jesús Viguera Molins. La falta de referencia a la advocación del Pilar no deja de ser extraña, aunque pudiera existir una iglesia dedicada a la Virgen desde antes de la conquista musulmana de 716, en época visigótica, de la que no poseemos noticia alguna.

$26 \mathrm{Ni}$ siquiera hoy $\mathrm{H}$. Espinosa, 2018, p. 150, está en condiciones de "asociar con la fábrica primitiva de la Santa Capilla los elementos arqueológicos rescatados durante las excavaciones efectuadas en el subsuelo de la [actual] basílica y su entorno...".

27 Solamente cita la basílica y catedral de San Vicente de Zaragoza, la basílica de Santa Engracia y los Dieciocho mártires, y la basílica de San Millán. R. Gonzálvez Ruiz, San Ildefonso y otros obispos de la iglesia visigótica y mozára- be de Toledo, Cabildo Primado, Toledo, 2018, pp. 47-120.

28 L. García Iglesias, Zaragoza ciudad visigoda, Guara, Zaragoza, 1979, pp. 85-91, ha insistido en que no existe ni documento ni apoyo menor ni resto arqueológico que pueda sostener la existencia de una basílica o iglesia dedicada a Santa María en la Zaragoza de época visigótica.

$29 \mathrm{Ni}$ rastro en J. Fontaine, L'art préroman hispanque. L'art mozarabe, Zodiaque, La Pierre-qui-Vire, 1977 o en I. G. Bango Torviso, Arte prerrománico hispano. El arte en la España cristiana de los siglos VI al XI, Summa Artis VIII-II, Espasa Calpe, Madrid, 2001, si exceptuamos la aparición del nombre de un obispo Elleca o Ellecne en Oviedo en el 893 y de nuevo en 906, que podría haberlo sido in partibus infidelium. M. Carriedo Tejedo, "Cronología de los obispos de Castilla en los siglos VIII-X (Osma-Muñó, Veleya-Valpuesta y Oca-Burgos)", Edad Media. Revista de Historia, 5, 2002, pp. 69-116.

30 D. Lasabagaster Arratibel, La Joya de Zaragoza; el Pilar de Santa Maria, Tipo Línea, Zaragoza, 1988. La documentación parece referirse al pontificado de Bonifacio VIII (1294-1303). Diego de Espés, en su Historia eclesiástica de la Ciudad de Zaragoza desde la venida de J.C. Señor y Redentor nuestro, hasta el año 1575, redactada entre 1575 y 1578, apuntó la fecha de 1240 para la Capilla del Pilar. Hycka Espinosa, 2018, ap. documenta la advocación del Pilar desde 1435 y Capilla del Pilar desde 1454; la referencia al Santo Pilar, desde 1486

31 Ahora C. Morte García, Damián Forment, escultor del Renacimiento, CAl, Zaragoza, 2009.

32 Citamos, por desconfiar de las traducciones al castellano, por la edición latina "Itinerarium hispanicum Hieronymi Monetarii 1494-1495", ed. Ludwig Pfandl, Revue Hispanique, 48, 113, 1920, pp. 1-179, esp. p. 139.

33 Tradicionalmente atribuido a Domingo Yarza y fechado en 1725, Ríos Balaguer, 1926, doc. 29, lo identificó con un dibujo anónimo de 1732.

Informe impreso del VI Conde de Peralada Guillermo de Rocafull y Rocabertí (d. 1672-1728), de 1725, en
Madrid, AHN, Legajo 426/27 (pero hoy ilocalizable con esta signatura que se citaba). También B. Boloqui Larraya y A. Ansón Navarro, "Catedral Basílica de Ntra. Sra. Del Pilar", en Las catedrales de Aragón, Caja de Ahorros de Zaragoza, Aragón y Rioja, Zaragoza, 1987, pp. 243-306, p. 305, n. 93-94 y Ansón y Boloqui, 1988

Hoy cabría pensar que el proyecto desconocido de Miguel Jerónimo Lorieri (1690-1749) de 1732 sería el que pudo mandarse a Madrid, dado que, desde ese mismo año, era pintor del rey, para que lo viera en 1735 Filippo Juvarra, antes del diseñado por parte del lego jesuita Pablo Diego Ibáñez (1737). Sobre aquél, M. Hermoso Cuesta, "El nombramiento de Miguel Jerónimo Lorieri como pintor del rey (y una nota sobre Corrado Giaquinto)", Artigrama, 18, 2003, 425434.

34 Tropheos y antigüedades de la imperial ciudad de Zaragoza y general historia..., Sebastián de Cormellas, Zaragoza, 1639, pp. 241, 367 y 398.

${ }^{35}$ Descripción histórico-panegírica, de las solemnes demonstraciones festivas... al nuevo Templo de Nuestra Señora del Pilar, Herederos de Manuel Román, Zaragoza, 1719, pp. 7 y 68.

${ }^{36}$ Aramburu, 1766, pp. 74-75.

37 Fundación milagrosa de la CapiIla angélica y apostólica de la Madre de Dios del Pilar, y excelencias de la imperial ciudad de Zaragoza, Sebastián Mateuad, Barcelona, 1616, pp. 102-103.

38 Aunque se haya datado en 1435/1438, atribuyéndola al escultor Juan de la Huerta de Daroca como donación de la reina Blanca de Navarra y del arzobispo Dalmau de Mur; véase M. del C. Lacarra Ducay, "Zaragoza barroca", en Guía histórico-artística de Zaragoza, ed. G. Fatás Cabeza, Ayuntamiento, Zaragoza, 1991, p. 310 y "La devoción a Santa María del Pilar de Zaragoza durante la Baja Edad Media", en El Pilar es la Columna. Historia de una devoción, Gobierno de Aragón y Ayuntamiento de Zaragoza, Zaragoza, 1995, pp. 29-58. También M. I. Falcón Pérez, "Religiosidad popular en Zaragoza en el Siglo XV", en F. J. Campos y Fernández de Sevilla (ed.), Religiosidad popular en España. Actas del Simposium (1-4 de septiembre de 1997), Real Colegio Uni- 
versitario Escorial María Cristina, San Lorenzo de El Escorial, 1997, pp. 877-898, esp. p. 881.

39 P. González Serrano, "Divinidades y vírgenes de cara negra", Revista Digital de Iconografía Medieval, ix, 17, 2017, pp. 45-60, en una línea mitográfica, sobre W. Rincón García, El Pilar de Zaragoza, Everest, León, 2000.

40 F. Marías, "Definición y límites del mecenazgo: en singular, dual y plural, con la basílica del Pilar al fondo", en J. Ibáñez Fernández (ed.), Del mecenazgo a las nuevas formas de promoción artística. Actas del XIV Coloquio de Arte Aragonés, Universidad de Zaragoza, Zaragoza, 2017, pp. 103-142 y "Ventura Rodríguez: proyectos y fábricas de catedrales", en D. Rodríguez Ruiz (ed.), Ventura Rodríguez. Arquitecto de la llustración, Comunidad de Madrid, Madrid, 2017, pp. 90-115.

${ }^{41}$ Boloqui y Ansón, 1987, pp. $280-$ 282.

42 Véase el esbozo dibujado de Rodríguez de 1751 (?), del Archivo de la Real Academia de San Fernando de Madrid (Legajo 2-33-1), en Buesa Conde, 2016, p. 22.

43 F. Gutiérrez Lasanta, Historia de la Virgen del Pilar, Zaragoza, 1973, III (EI Templo de Nuestra Señora del Pilar), p. 288; Ansón y Boloqui, 1988, pp. 50-52, insisten en su destrucción.

44 Aramburu, 1766, pp. 80 y $82-$ 84. Su descripción de la Capilla antigua en pp. 85-92.

${ }^{45}$ Aramburu, 1766, pp. 83-84, las cursivas son nuestras.

46 "[La] de Granada tuvo lugar para salvar a Santiago del peligro de muerte al que se vio expuesto como consecuencia de su predicación. La Virgen se le apareció, le libró, y Santiago continuó su actividad en España, en muchos lugares de la Andalucía. Vino después a Toledo, y de allí pasó a Portugal y a Galicia, y por Astorga y divirtiéndose a diferentes lugares llegó a la Rioja y por Logroño pasó a Tudela y Zaragoza, donde sucedió lo que diré en el capítulo siguiente. Por toda esta peregrinación fue Santiago dejando discípulos por obispos en diferentes ciudades de España y plantando la fe y culto divino. $Y$ fueron tantos $y$ tan prodigiosos los milagros que hizo en este reino, que no han de parecer increíbles los que se saben, porque son muchos más los que se ignoran. El fruto que hizo con la predicación fue inmenso, respecto del tiempo que estuvo en España, y ha sido error decir o pensar que convirtió muy pocos, porque en todas las partes o lugares que anduvo dejó plantada la fe, y para eso ordenó tantos obispos en este Reino, para el gobierno de los hijos que había engendrado en Cristo". Han comentado este texto T. Domingo Pérez, "La Tradición", en El Pilar de Zaragoza, CAl, Zaragoza, 1984, pp. 17-30 y T. Domingo Pérez y M. Artigas, "La tradición del Pilar en Sor María de Jesús de Ágreda", Scripta de Maria, 2, 2005, pp. 287-315. Véase también, en un contexto más amplio, C. Colahan, The Visions of Sor Maria de Ágreda. Writing Knowledge and Power, University of Arizona Press, Tucson, 1994 y M. Tausiet Carlés, "Zaragoza celeste y subteránea. Geografía mítica de una ciudad (siglos XV-XVIII)", en F. Delpech (ed.), L'imaginaire du territoire en Espagne et au Portugal (XVIe-XVIle siècles), Casa de Velázquez, Madrid-París, 2008, pp. 141170.

47 Juan Jolis, Barcelona, 16752 ; Miguel Manescal, Lisboa, $1680^{3}$ y $1684^{4}$; Viuda de Juan de Figuerola, Perpiñán, $1685^{5}$.

48 Pérez y Artigas, 2005, p. 288. El texto de Sor María fue recogido por R. A. Faci, Aragón, Reyno de Christo, y dote de María SSma. fundado sobre la columna immóvil de Nuestra Señora en su Ciudad de Zaragoza, Joseph Ferrer, Zaragoza, 1739 (ed. facsímil, DGA, Zaragoza, 1979).

$$
49 \text { AEPZ, Almario 1, caja. 1, legajo }
$$
$1, \mathrm{v}$.

50 A. Valderas, Bibliografía histórica leonesa: Juan de Ferreras García (1652/1735): estudio bio-bibliográfico, Universidad, León, 2000.

51 La religiosa continuaba: "Dio fin la gran Reina a su razonamiento, mandando a los ángeles que colocasen la columna y sobre ella la santa Imagen en el mismo lugar y puesto que hoy están, y así lo ejecutaron en un momento. Luego que se erigió la columna y se asentó en ella la sagrada Imagen, los mismos ángeles, y también el santo apóstol, reconocieron aquel lugar y título por casa de Dios, puerta del cielo y tierra santa y consagrada en templo para gloria del Altísimo e invocación de su beatísima Madre. $Y$ en fe de esto dieron culto, adoración y reverencia a la divinidad, y Santiago se postró en tierra, y los ángeles con nuevos cánticos celebraron los primeros con el mismo apóstol la nueva y primera dedicación de templo que se instituyó en el orbe después de la redención humana y en nombre de la gran Señora del cielo y tierra. Este fue el origen felicísimo del santuario de Nuestra Señora del Pilar de Zaragoza, que con justa razón se llama cámara angelical, casa propia de Dios y de su Madre purísima, y digna de la veneración de todo el orbe y fiador seguro y abonado de los beneficios y favores del cielo, que no desmerecieron nuestros pecados. Paréceme a mi que nuestro gran patrón y apóstol el segundo Jacobo dio principio más glorioso a este templo que el primer Jacobo al suyo de Betel, cuando caminaba peregrino a Mesopotamia, aunque aquel título y piedra que levantó fuese lugar del futuro templo de Salomón" (pp. 352-353).

"Pasada la visión de María santísima -proseguía nuestra religiosa-, Ilamó Santiago a sus discípulos, que de la música y resplandor estaban absortos, aunque ni oyeron ni vieron otra cosa. $Y$ el gran maestro les dio noticia de lo que convenía, para que le ayudasen en la edificación del sagrado templo, en que puso mano y diligencia; $y$ antes de partir de Zaragoza acabó la pequeña capilla donde está la santa Imagen y columna, con favor y asistencia de los ángeles. Y después con el tiempo los católicos edificaron el suntuoso templo y lo demás que adorna y acompaña aquel tan celebrado santuario" (p. 357)

52 Pérez y Artigas, 2005, pp. 295298, al interrogarse sobre las fuentes de Sor María, se preguntan si habría conocido el texto interpolado en el citado códice de las "Moralia in Job" (578-595) de san Gregorio Magno, de finales del siglo XIII o comienzos del XIV, algo improbable.

53 La primera edición, en valenciano, Primera part d'la historia de Valencia que tracta de las antiguedades de Spahnya y fundació de Valencia, fue publicada en Joan Mei, Valencia, 1538 (fol. xlviii) y 1554 (ed. V. Josep Escartí, Valencia, 1998, pp. 139-140). V. Josep Escartí, 
"Dades sobre Pere Antoni Beuter i la Primera Part de la Història de València (València, 1538)", Espéculo: Revista de Estudios Literarios, 44, 2010, pp. 1-29.

También quizá en el texto de Juan Tamayo Salazar (1602-1661), quien había publicado en 1658 su Martyrologium Hispanum Anamnesis o Commemoratio omnium ss. Hispanorum, Pontyficum, Martyrum, Confessorum, Virginum, Viduarum, ac sanctarum mulierum (6 vols., Lyon, 1651-1659, V, 1658, p. 506), donde se volvía a insistir en la antigüedad de la iglesia y en la Capilla levantada por el propio Santiago; a su vez, Tamayo se basaba en su publicación previa, de 1648, del poema latino sobre la venida de Santiago a España y la Virgen del Pilar (reproduciendo algún pasaje de la Apparitio b. Mariae de Pilari), con otros poemas, del supuesto Aulo Halo, poeta nacido en Burdeos y establecido en Toledo, según la biografía que le inventó Jerónimo Román de la Higuera, su Auli Hali poetae burdigalensis, civisque toletani, De adventu in Hispanias S. Jacobi Zebedaei filii... Diego Díaz de la Carrera, Madrid, 1648, pp. 59-60.

Añádanse los textos de H. Cock, Relación del viaje hecho por Felipe II en 1585 a Zaragoza, Barcelona y Valencia, Aribau, Madrid, 1876; J. Fernández de Velasco, Dos discursos en que se defiende la venida y predicación del apóstol Santiago a España, Juan Hetsroy, Amberes, 1608; D. del Castillo, Defensa de la venida y predicación evangélica de Santiago en España, dirigida al rey don Felipe III por el doctor don Diego del Castillo, Prior y canónigo de la Santa Iglesia de Palencia, que es traduzido de lo que en latín presentó en Roma a la Santidad de Clemente VIII el año de mil y seycientos, Lorenço de Robles, Zaragoza, 1608; E. Serrano Martín, El Pilar, la historia y la tradición: la obra erudita de Luis Díez de Aux (1562-ca. 1630), Mira, Zaragoza, 2014, pp. 77-99; "Silentium facite: El fin de la polémica y el discurso en torno a la Virgen del Pilar en la Edad Moderna", Hispania, 74, 248, 2014, pp. 687-714 y "Milagros, devoción y política a propósito de la virgen del Pilar en la edad moderna", en Utopías, sueños y quimeras (España, siglos XVI y XVII) - Utopies, rêves et chimères (Espagne, XVIe-XVIle siècles). Una encrucijada de sueños, e-Spania, 2015 https://journals. openedition.org/e-spania/24814.

54 Parece ya totalmente aclarado el problema de esta cronología proyectual de Ventura Rodríguez. A pesar de la fecha dada por Antonio Ponz (1788, septiembre de 1753), y Ceán Bermúdez (1800, nombramiento de 1750 y viaje a Zaragoza en 1753), Demetrio Ríos Balaguer (1925, pp. 21-27) sostuvo el viaje de Rodríguez el 15 diciembre de 1750 en lugar de septiembre; así ha insistido Esteban Lorente, 1992, p. 486, criticando a T. F. Reese, The Architecture of Ventura Rodríguez, Garland, Nueva York, 1976, II, p. 78, n. 66, por afirmar que había firmado los planos en Madrid, el 20 de noviembre de 1750, y por tanto antes de ir a Zaragoza el 17 de diciembre.

55 Fotografía del catálogo de la exposición de la Dirección General de Patrimonio Cultural de la Comunidad de Madrid D. Rodríguez Ruiz (ed.), Ventura Rodríguez. Arquitecto de la llustración, Comunidad de Madrid, Madrid, 2017, n. ${ }^{\circ}$ 64. Nuestro agradecimiento a María del Carmen García Fresneda por procurárnosla.

56 Historia chronológica de la Santa, Angélica y Apostólica Capilla de Nuestra Señora del Pilar de la ciudad de Zaragoza y de los progresos de sus edificaciones..., Imprenta del Rey, Zaragoza, 1766.

57 Agradecemos a su nieto, el también arquitecto Teodoro Ríos Solá, la amabilidad al permitirnos disponer de estos dibujos.

Sobre Ríos Balaguer, L. Aldama Fernández, "Teodoro Ríos Balaguer, arquitecto restaurador e investigador de la Basílica del Pilar: Proyectos de consolidación (1923-1930)", en M. S. García Guatas, J. P. Lorente Lorente e I. A. Yeste Navarro (eds.), La ciudad de Zaragoza de 1908 a 2008, Instituto "Fernando el Católico", Zaragoza 2009, pp. 353-366.

58 J. F. Esteban Lorente, "Ventura Rodríguez al servicio de una idea: la Santa Capilla de la Virgen del Pilar de Zaragoza", Artigrama, 4, 1987, pp. 157-206 y "Las ocultas ideas de clientes, patronos y arquitecto en la construcción de la Santa Capilla del Pilar de Zaragoza", en Patronos, promotores, mecenas y clientes VII CEHA Murcia, 1988, Uni- versidad de Murcia, Murcia, 1992, pp. 483-494, p. 486, aunque sin publicar los documentos 1-3 a los que se refiere en el texto que ya había reproducido en 1987.

${ }^{59}$ Citando las "Gestas Capitulares" del cabildo del 22 de febrero de 1737; véase $B$. Boloqui Larraya, "Los escultores académicos hermano jesuita Pablo Diego Ibáñez (conocido como Lacarre), José Ramírez de Arellano y el platero de S. M. Francisco Diego Lacarra: relaciones familiares a través de los "Quinqui Libri" y el Archivo General de los jesuitas en Roma", en Tercer Encuentro de Estudios Bilbilitanos: Actas, Instituto de Estudios Bilbilitanos, Calatayud, 1, 1992 pp. 373407; y Ansón Boloqui, 1988, pp. 32-38; F. B. Medina, "Pablo Diego Ibáñez", Ch. E. O’Neil y J. M. ${ }^{a}$ Domínguez Ortiz (eds.), Diccionario histórico de la Compañía de Jesús. Biográfico-temático, Universidad Pontificia de Comillas, Madrid, 2001, II, p. 1.118; J. Ibáñez Fernández y J. Criado Mainar, "La arquitectura jesuítica en Aragón. Estado de la cuestión", en M. ${ }^{a}$ I. Álvaro Zamora, J. Ibáñez Fernández y J. Criado Mainar (eds.), La arquitectura jesuítica en Aragón. Actas del Simposio 2010, Institución "Fernando el Católico", Zaragoza, 2012, pp. 393-472.

60 En Esteban Lorente, 1987, doc. 1, pp. 182-183 (Madrid, Real Academia de San Fernando, Archivo, Legajo 2-331). También se recoge en el anónimo doc. 3, pp. 183-184: "(por la precisión de mantener la pared que hace espaldas al altar) que el principal objeto de esta obra que Nuestra Señora sale del centro de ella, y siendo del ánimo de V.I. el mantener la memoria con esta nueva fábrica, no puedo dejar de decir, (según las reglas de la arquitectura), que se aparta de la tradición la medida de este distrito, por exceder su largueza a la figura dupla, en la que los más autores convienen tuvo la Santa Capilla, por los ocho de ancho y diez y seis de largo, que es figura perfecta, en donde infiero colocarían la Santa Imagen en medio de su testera, que hace frente a1 oriente, además de ésto, por la parte del Santo Pilar, que hace espaldas a Nuestra Señora noto un pedazo de pared antigua dividida de la moderna, con su marco, y sobrepuesto de medio relieve los Convertidos y que en medio de esta pared, con toda simetría, está el Santo Pilar y puesto por don- 
de se adora, y en todo lo demás de las paredes que circundan la Santa Capilla no he notado esta singularidad, antes bien en su grueso se distingue de ésta".

61 También se señalaba en la "Elevación exterior" con las mitades oeste y este, y en el que se mostraba "Por el hueco $\mathrm{H}$ se ha de adorar el Santo Pilar".

62 Hycka Espinosa, 2018, ap. iv, p. 491, adelanta la fecha de este dibujo (ACP, Almario 6-4-1-39) del conjunto de la basílica al periodo 1610/1617.

${ }^{63}$ Hycka Espinosa, 2018, ap. v, pp. 157 y 492-493, fecha en 1617/1632 [pero podría ser incluso posterior] otro dibujo (ACP, Almario 6-11-2-6) del conjunto del espacio claustral donde se insertaba la Capilla.

${ }^{64}$ Itinerario del Reino de Aragón, de 1610-1611, Diputación, Zaragoza, 1895 y 2006; recogido por Hycka Espinosa, 2018, p. 157.

65 Marías, 2017, pp. 103-142

66 Lógicamente nada en Esteban Lorente, 1992, pp. 483-494, ni ahora en R. Usón García, "La Santa Capilla del Pilar de Zaragoza", en D. Rodríguez Ruiz (ed.), Ventura Rodríguez. Arquitecto de la Ilustración, Comunidad de Madrid, Madrid, 2017, pp. 314-319 y previamente en La intervención de Ventura Rodríguez en el Pilar. La Santa Capilla generatriz de un sueño arquitectónico, Colegio Oficial de Arquitectos de Aragón, Zaragoza, 1990.

67 Sobre el tema, S. F. Ostrow, "Gialorenzo Bernini, Girolamo Lucenti, and the Statue of Philip IV in S. Maria Maggiore: Patronage and Politics in Seicento Rome", The Art Bulletin, 73, 1991, pp. 89-118; T. J. Dandelet, Spanish Rome 1500-1700, Yale University Press, New Haven-Londres, 2001 (trad. esp. La Roma española, (1500-1700), Barcelona, Crítica, 2002); M. Jacogz, Figure, liturgia e culto, arte: Ricerche dall'Archivio della Basilica Papale di Santa Maria Maggiore, 1, Lisanti, Roma, 2012 y especialmente S. Guido, "Il Filippo IV di Gianlorenzo Bernini e Girolamo Lucenti", en M. Jagosz (ed.), Figure, liturgia e culto, arte. Ricerche dall'Archivio della Basilica Papale di Santa Maria Maggiore, 2, Lisanti, Roma, 2013, pp. 213-236.

68 Compendio de los milagros de Nuestra Señora del Pilar de Zaragoça, primer templo del mundo, edificado en la Ley de Gracia, consagrado con assistencia personal de la Virgen Santíssima, viviendo en carne mortal, colocando los ángeles su primera piedra en la santa capilla por ara de la Sagrada Imagen que en ella se venera, proseguido por el Apóstol Santiago y sus discípulos, Herederos de Agustín Berges, Zaragoza, 1680.

69 Carta de Joseph de Villanueva, infantico de la Virgen del Pilar, a la muy Illustre Academia de Portugal, querellándose del escritor contra la tradición de la venida de Santiago a España, y la Divina Reina a Zaragoça, sin producir instrumento ni argumento nuevo y en ocasión tan importuna de estar estas materias decididas, Zaragoza-Madrid, 1723.

70 A. Nagel y C.Wood, Anachronic Renaissance, Zone Books, Nueva York, 2010, p. 209.

71 Véanse, por ejemplo, C. Hahn, Strange Beauty. Issues in the Making and Meaning of Reliquaries, 400-circa 1204, University Park, Penn State University Press, 2013 y S. Chaganti, The Medieval Poetics of Reliquary. Enshrinement, Inscription, Performance, Palgrave Macmillan, Nueva York-Basingstoke, 2008.

72 Nagel y Wood, 2010, pp. 198200; E. Alcalá, "Stones and Bricks, Tepetates and Gold: Material Translations between Holy Land, Italy, and New Spain", en G. Siracusano y A. Rodríguez Romero (eds.), Materia Americana. El "cuerpo" de las imágenes entre el arte, la ciencia y la cultura (siglos XVI-principios del XIX), Sáenz Peña, Eduntref, Buenos Aires, 2019 (en prensa). 168.

73 Hycka Espinosa, 2018, pp. 166 -

74 C. H. Lynch y P. Galindo Romeo, San Braulio obispo de Zaragoza (631-651) su vida y sus obras, Samaran, Madrid, 1950.

75 Hycka Espinosa, 2018, p. 150, los vincula con la basílica de Santa María la Mayor o del Pilar, aunque ya hayamos hecho referencia al silencio generalizado.

76 Véase esta cita en la exposición del Alma Mater Museum de 2016,

https://diocesisdejaca.org/index. php/iglesia-en-aragon/569--15/file y https://studylib.es/doc/8616188/201610-16-arte
77 Véase esta cita también en la citada exposición del Alma Mater Museum de 2016.

78 Véase la "Memoria de Fray Lope de Marco [arzobispo Hernando de Aragón]" en J. Ibáñez Fernández, Splendor Verolae. El monasterio de Veruela entre 1535 y 1560, Centro de Estudios Turiasorenses, Zaragoza, 2001, p. 256; agradecemos vivamente al autor el habernos señalado esta referencia tan preciosa como desapercibida, y quien pone al día su propia transcripción. Hycka Espinosa, 2018, ap. 41, pp. 582-583, que no cita esta fuente, recoge la visita pastoral de 1606 del obispo de Barbastro, Juan Móriz de Salazar, "cuya imagen halló sobre el Pilar [que en consecuencia no vio] con un manto riquísimo... a un lado avía muchas presentallas de piernas, cabezas y figuras de plata..." como exvotos.

79 Véase D. J. Buesa Conde, La Sagrada Columna. El Pilar de Aragón, Alma Mater Museum, Zaragoza, 2016, 22-24; éste, director del museo, ha señalado que se ha documentado que el material original era un cuarzo opaco de colores variados procedente de las canteras de Tortosa, definición que parece proceder de la descripción de 1756 de Manuel Vicente de Aramburu, que la definió como "de cuarzo opaco de colores variados, generalmente veteado y frecuentemente rojizo por la presencia de óxido de hierro". También M. Ortí, "La projecció catalana i europea del marbre brocatell de Tortosa", Recerca, 16, 2015, pp. 121-161, esp. p. 126, señala la procedencia de las canteras de Tortosa de las columnas de la Aljafería y de la columna, supuestamente de época romana, del Pilar de Zaragoza. Sobre el empleo imperial, llegando a Roma en época de los Severos (193-235), de este mármol brocatel, P. Pensabene, Marmi antichi II. Cave e tecnica di lavorazione. Provenienze e distributione, Roma, L'Erma di Bretschneider, 1998; P. Pensabene, L. Lazzarini, M. De Nuccio y L. Ungaro (eds.), I marmi colorati della Roma imperiale, Comune di Roma-Marsilio, Roma, 2002, pp. 273-274.

${ }^{80}$ Fray J. de San José, "Historia de Nuestra Señora del Pilar de Çaragoza", Zaragoza, 1647, Madrid, Biblioteca Nacional de España, Ms. 7224. 
81 Sobre las imágenes, J. Criado Mainar, "Santiago Apóstol y el Pilar de Zaragoza. El papel de las imágenes en el debate pilarista a comienzos del siglo XVII", en A. Cabeza Duplá Ansuategui, M. ${ }^{a}$ V. Escribano Paño et. alt., Miscelánea de estudios en homenaje a Guillermo Fatás, Diputación, Zaragoza, 2014, pp. 207-213.

82 Hycka Espinosa, 2018, pp. 168-169.

83 M. Gay publicó en 1934, en El Heraldo de Aragón, la aparición de co- lumnas y capiteles musulmanes del siglo $\mathrm{XI}$, junto a restos romanos, en las excavaciones emprendidas en el subsuelo de la basílica poco antes por Teodoro Ríos Balaguer. Es posible que procediera de las columnas del teatro de Caesaraugusta, del siglo I y descubierto en 1972, aunque no se hayan encontrado fustes de columnas romanas en esta zona, sino en El Coso, por ejemplo.

84 Sobre la existencia de edificaciones islámicas o de una mezquita en el sitio del Pilar antes de la iglesia de Santa María del Pilar, nada sabemos; solo existen noticias en la Zaragoza musulmana de la aljama mayor (después la Seo) y el oratorio de la Aljafería. Véase S. Calvo Capilla, Las mezquitas de al-Andalus, Fundación Ibn Tufayl, Almería, 2015.

85 E. Hobsbawm y T. Ranger, The Invention of Tradition, Cambridge University Press, Cambridge, 1983; ed. esp. La invención de la tradición, Crítica, Barcelona, 1987, p. 16. 


\section{REFERENCIAS}

Alcalá, Elena. 2019. "Stones and Bricks, Tepetates and Gold: Material Translations between Holy Land, Italy, and New Spain." En Materia Americana. El "cuerpo" de las imágenes entre el arte, la ciencia y la cultura (siglos XVI-principios del XIX), Gabriela Siracusano y Agustina Rodríguez Romero, editores. Buenos Aires: Sáenz Peña, Eduntref (en prensa).

Aldama Fernández, Laura. 2009. “Teodoro Ríos Balaguer, arquitecto restaurador e investigador de la Basílica del Pilar: Proyectos de consolidación (1923-1930)." En La ciudad de Zaragoza de 1908 a 2008, 353-366, Manuel S. García Guatas, Jesús P. Lorente Lorente e Isabel A. Yeste Navarro, editores. Zaragoza: Instituto "Fernando el Católico".

Alturo i Perucho, Jesús. 2012. "El testamento sacramental de Moción del año 987 y su redactor, el juez Ervigio Marco." En Homenaje al Prof. Dr. José Ignacio Fernández de Viana y Vieites, Rafael Marín López, editor, 29-44. Granada.

Amada, José Félix. 1680. Compendio de los milagros de Nuestra Señora del Pilar de Zaragoça, primer templo del mundo, edificado en la Ley de Gracia, consagrado con assistencia personal de la Virgen Santíssima, viviendo en carne mortal, colocando los ángeles su primera piedra en la santa capilla por ara de la Sagrada Imagen que en ella se venera, proseguido por el Apóstol Santiago y sus discípulos. Zaragoza: Herederos de Agustín Berges.

Ansón, Arturo, y Belén Boloqui. 1998. La Santa Capilla del Pilar. Zaragoza: Caja Inmaculada.

Aramburu, Manuel Vicente. 1766. Historia chronológica de la Santa, Angélica y Apostólica Capilla de Nuestra Señora del Pilar de la ciudad de Zaragoza y de los progresos de sus edificaciones. Zaragoza: Imprenta del Rey.

Aranda Pérez, Francisco J. 2014. "De invenciones, controversias y polémicas historiográficas y políticas en la Monarquía Hispánica en tiempos de Quevedo (y aún un siglo después)." La Perinola 18: 15-61. https://doi. org/10.15581/017.22.201-246
Arbaiza Blanco-Soler, Silvia, y Carmen Heras Casas. 1994. "Legado de D. Silvestre Pérez a la Real Academia de San Fernando (Exposición Enero-Abril 1994)." Academia 79: 341-386.

Bango Torviso, Isidro G. 2001. Arte prerrománico hispano. El arte en la España cristiana de los siglos VI al XI, Summa Artis VIII-II. Madrid: Espasa-Calpe.

Barrios Aguilera, Manuel y, Mercedes García-Arenal, editores. 2006. Los plomos del Sacromonte: invención y tesoro. Valencia: Universidad de Valencia.

Bernon, Aimond de. 1806. Historia translationis S. Vicentii levitae et mart. ex Hispania ad Castrense in Gallia monasterium: auctore Aimonio monacho ord. S. Benedicti. Madrid: Imprenta Real.

Bernon, Aimond de. 1806. Viaje Literario a las iglesias de España. Ed. J. Lorenzo Villanueva. Madrid: Imprenta de Fortanet-Real Academia de la Historia.

Boloqui Larraya, Belén, y Arturo Ansón Navarro. 1987. "Catedral Basílica de Ntra. Sra. Del Pilar." En Las catedrales de Aragón, 243-306. Zaragoza: Caja de Ahorros de Zaragoza, Aragón y Rioja, Zaragoza.

Boloqui Larraya, Belén. 1984. Escultura zaragozana en la época de los Ramírez, 1710-1780. Granada: Ministerio de Cultura.

Boloqui Larraya, Belén. 1992. “Los escultores académicos hermano jesuita Pablo Diego lbáñez (conocido como Lacarre), José Ramírez de Arellano y el platero de S. M. Francisco Diego Lacarra: relaciones familiares a través de los "Quinqui Libri" y el Archivo General de los jesuitas en Roma." En Tercer Encuentro de Estudios Bilbilitanos: Actas, 373-407. Calatayud: Instituto de Estudios Bilbilitanos.

Buesa Conde, Domingo J. 2016. La Sagrada Columna. El Pilar de Aragón. Zaragoza: Alma Mater Museum.

Calvo Capilla, Susana. 2015. Las mezquitas de al-Andalus. Almería: Fundación Ibn Tufayl.

Cardaillac, Louis. 2002. Santiago Apóstol. El santo de los dos mundos. Guadalajara: El Colegio de Jalisco. 
Carriedo Tejedo, Manuel. 2002. "Cronología de los obispos de Castilla en los siglos VIII-X (Osma-Muñó, Veleya-Valpuesta y Oca-Burgos)." Edad Media. Revista de Historia 5: 69-116.

Castillo, Diego del. 1608. Defensa de la venida y predicación evangélica de Santiago en España, dirigida al rey don Felipe III por el doctor don Diego del Castillo, Prior y canónigo de la Santa Iglesia de Palencia, que es traduzido de lo que en latín presentó en Roma a la Santidad de Clemente VIII el año de mil y seycientos. Zaragoza: Lorenço de Robles.

Chaganti, Seeta. 2008. The Medieval Poetics of Reliquary. Enshrinement, Inscription, Performance. Nueva York-Basingstoke: Palgrave Macmillan. https://doi.org/10.1017/ s0038713410000151

Cock, Henrique. 1876. Relación del viaje hecho por Felipe II en 1585 a Zaragoza, Barcelona y Valencia. Madrid: Aribau.

Colahan, Clark A. 1994. The Visions of Sor Maria de Ágreda. Writing Knowledge and Power. Tucson: University of Arizona Press. https://doi. org/10.2307/3169733

Coleman, David. 2003. Creating Christian Granada: Society and Religious Culture in an Old-World Frontier City, 1492-1600. IthacaLondres: Cornell University Press. https://doi. org/10.1086/ahr/109.5.1648

Criado Mainar, Jesús. 2014. "Santiago Apóstol y el Pilar de Zaragoza. El papel de las imágenes en el debate pilarista a comienzos del siglo XVII." En Miscelánea de estudios en homenaje a Guillermo Fatás, Antonio Cabeza Duplá Ansuategui, María Victoria Escribano Paño, et. alt., 207-213. Zaragoza: Diputación.

Dandelet, Thomas J. 2001. Spanish Rome 15001700. New Haven-Londres: Yale University Press. https://doi.org/10.1086/ahr/108.1.281

Descripción histórico-panegírica, de las solemnes demonstraciones festivas... al nuevo Templo de Nuestra Señora del Pilar. 1719. Zaragoza, Herederos de Manuel Román.

Díaz y Díaz, Manuel C. 2010. Estudios jacobeos. Santiago de Compostela: Universidad de Santiago.
Domingo Pérez, Tomás. 1984. "La Tradición." En El Pilar de Zaragoza, 17-30. Zaragoza, Caja Inmaculada.

Domingo Pérez, Tomás. 2005. “La tradición del Pilar en Sor María de Jesús de Ágreda." Scripta de Maria 2: 287-315.

Escartí, Josep. 2010. “Dades sobre Pere Antoni Beuter i la Primera Part de la Història de València (València, 1538)." Espéculo: Revista de Estudios Literarios 44: 1-29.

Esteban Lorente, Juan Francisco. 1987. “Ventura Rodríguez al servicio de una idea: la Santa Capilla de la Virgen del Pilar de Zaragoza." Artigrama 4: 157-206.

Esteban Lorente, Juan Francisco. 1992. "Las ocultas ideas de clientes, patronos y arquitecto en la construcción de la Santa Capilla del Pilar de Zaragoza." En Patronos, promotores, mecenas y clientes VII CEHA Murcia, 1988, 483-494. Murcia: Universidad de Murcia.

Eugenii Toletani Opera Omnia. 2005. Ed. P. Farmhouse Alberto. Turnhout: Brepols.

Faci, Roque Alberto. 1739. Aragón, Reyno de Christo, y dote de María SSma. fundado sobre la columna immóvil de Nuestra Señora en su Ciudad de Zaragoza. Zaragoza: Joseph Ferrer.

Falcón Pérez, María Isabel. 1997. "Religiosidad popular en Zaragoza en el Siglo XV." En Religiosidad popular en España. Actas del Simposium (1-4 de septiembre de 1997), Francisco J. Campos y Fernández de Sevilla, Francisco, editor, 877-898. San Lorenzo de El Escorial: Real Colegio Universitario Escorial María Cristina.

Fernández de Velasco, Juan. 1608. Dos discursos en que se defiende la venida y predicación del apósto/ Santiago a España, Amberes: Juan Hetsroy.

Fita, Fidel. 1904. "El Pilar de Zaragoza. Su templo y su tradición histórica hasta el año 1324." Boletín de la Real Academia de la Historia 44 (6): 525.

Fontaine, Jacques. 1977. L'art préroman hispanque. L'art mozárabe. La Pierre-qui-Vire: Zodiaque.

Fundación milagrosa de la Capilla angélica y apostólica de la Madre de Dios del Pilar, y ex- 
celencias de la imperial ciudad de Zaragoza. 1616. Barcelona: Sebastián Mateuad.

García Iglesias, Luis. 1979. Zaragoza ciudad visigoda. Zaragoza: Guara.

García Moreno, Luis A. 1996. "La monarquía visigoda y la Iglesia en Levante: las raíces de un país." Alebus: Cuadernos de Estudios Históricos del Valle de Elda 6: 7-30. https://doi. org/10.3989/hs.1997.v49.i99.669

García Moreno, Luis A. 2012. "Santiago y los varones apostólicos en la España altomedieval: ¿enfrentados o complementarios?" En El mediterráneo en el origen. IX Congreso Internacional de Asociaciones Jacobeas, Amparo Sánchez Ribes, editor, 15-26. Valencia: Asociación Amigos del Camino de Santiago de la Comunidad Valenciana.

García Villada, Zacarías, SI. 1929. Historia eclesiástica de España, I, 1. ${ }^{a}$ parte. Madrid: Compañía Ibero-Americana de Publicaciones.

García-Arenal, Mercedes, y Fernando Rodríguez Mediano. 2010. Un Oriente español. Los moriscos y el Sacromonte en tiempos de Contrarreforma. Madrid: Marcial Pons. https://doi. org/10.1163/18778372-13410110

García-Arenal, Mercedes, y Fernando Rodríguez Mediano. 2013. The Orient in Spain. Converted Muslims, The Forged Lead Books of Granada, and the Rise of Orientalism. LeidenBoston: Brill. https://doi.org/10.1080/004872 1x.2015.1075124

García-Arenal, Mercedes, y Fernando Rodríguez Mediano, eds. 2008. La ¿Historia inventada? Los Libros plúmbeos y el legado sacromontano. Granada: Universidad de Granada.

Gil Pujol, Xavier. 2019. “El pastelero anticuario. Luis López y sus obras de Zaragoza en los años 1630 y 1640 ." En Mirando desde el puente. Estudios en homenaje al Profesor James S. Amelang, Fernando Andrés Robres, Mauro Hernández Benítez y Saúl Martínez Bermejo, editores, 71-81. Madrid: Universidad Autónoma.

González Serrano, Pilar. 2017. "Divinidades y vírgenes de cara negra." Revista Digital de Iconografía Medieval IX (17): 45-60.
Gonzálvez Ruiz, Ramón. 2018. San Ildefonso y otros obispos de la iglesia visigótica y mozárabe de Toledo. Toledo: Cabildo Primado.

Gonzálvez, Ramón, y Felipe Pereda. 1999. La catedral de Toledo 1549. Según el Doctor Blas Ortiz Descripción gráphica y elegantísima de la S.I. de Toledo. Toledo: Antonio Pareja Editor.

Gutiérrez Lasanta, Francisco. 1973. Historia de la Virgen del Pilar. Zaragoza.

Hahn, Cynthia. 2013. Strange Beauty. Issues in the Making and Meaning of Reliquaries, 400-circa 1204. University Park: Penn State University Press. https://doi.org/10.3202/caa. reviews.2018.135

Harris, A. Katie. 2007. From Muslim to Christian Granada: Inventing a City's Past in Early Modern Spain. Baltimore: Johns Hopkins University Press. https://doi.org/10.14198/ shand.2008-2010.19.14

Heras Casas, Carmen, y Silvia Arbaiza BlancoSoler. 2000-2001. "Inventario de los dibujos arquitectónicos (de los siglos XVIII y XIX) en el Museo de la Real Academia de las Bellas Artes de San Fernando." Academia 91: 79-238; y 92-93: 103-271.

Hermoso Cuesta, Miguel. 2003. “El nombramiento de Miguel Jerónimo Lorieri como pintor del rey (y una nota sobre Corrado Giaquinto)." Artigrama 18: 425-434.

Hobsbawm, Eric, and Terence Ranger. 1983. The Invention of Tradition. Cambridge: Cambridge University Press. https://doi. org/10.2307/1159843

Hycka Espinosa, Olga. 2018. Santa María La Mayor y del Pilar de Zaragoza, evolución histórica del templo colegial. Zaragoza: Institución Fernando el Católico.

Ibáñez Fernández, Javier, y Jesús Criado Mainar. 2012. "La arquitectura jesuítica en Aragón. Estado de la cuestión." En La arquitectura jesuítica en Aragón. Actas del Simposio 2010, María Isabel Álvaro Zamora, Javier Ibáñez Fernández y Jesús Criado Mainar, editores, 393-472. Zaragoza: Institución "Fernando el Católico".

Ibáñez Fernández, Javier. 2001. "Memoria de Fray Lope de Marco [arzobispo Hernando de 
Aragón]." En Splendor Verolae. El monasterio de Veruela entre 1535 y 1560, Javier Ibáñez Fernández, 256. Zaragoza: Centro de Estudios Turiasorenses.

Itinerarium hispanicum Hieronymi Monetarii 1494-1495. 1920. Ed. Ludwig Pfandl, Revue Hispanique, 48, 113: 1-179.

Jacogz, Michal. 2012. Figure, liturgia e culto, arte: Ricerche dall'Archivio della Basilica Papale di Santa Maria Maggiore, 1. Roma: Lisanti.

Kagan, Richard L. (y colaboración de Marías, Fernando). 1998. Imágenes urbanas del mundo hispánico 1493-1780. Madrid: El Viso.

Kagan, Richard L. (y colaboración de Marías, Fernando). 2000. Urban Images of the Hispanic World, 1493-1793. New Haven-Londres: Yale University Press. https://doi.org/10.3138/ cjh.37.3.611

Lacarra Ducay, María del C. 1991. "Zaragoza barroca." En Guía histórico-artística de Zaragoza, Guillermo Fatás Cabeza, editor, 310. Zaragoza: Ayuntamiento.

Lacarra Ducay, María del C. 1995. "La devoción a Santa María del Pilar de Zaragoza durante la Baja Edad Media." En El Pilar es la Columna. Historia de una devoción, 29-58. Zaragoza: Gobierno de Aragón y Ayuntamiento de Zaragoza.

Lasabagaster Arratibel, Daniel. 1988. La Joya de Zaragoza; el Pilar de Santa Maria. Zaragoza: Tipo Línea.

Lynch, Charles H. y Galindo Romeo, Pascual. 1950. San Braulio obispo de Zaragoza (631651) su vida y sus obras. Madrid: Samaran. https://doi.org/10.2307/2853876

Magallón, Ana I., y José Carlos Martín. 2014. "La leyenda de la venida de la Virgen a Zaragoza (BHL 5388): edición crítica y estudio." Hagiographica. Rivista di agiografia e biografia della Societá Internazionale per lo Studio del Medioevo Latino XXI: 53-84.

Marías, Fernando. 2015. "Pintura, diplomacia y censura en la Cappella Paolina: desde Toledo y Madrid hasta Roma." En I rapporti tra Roma e Madrid nei secoli XVI e XVII: arte diplomazia e política, Alessandra Anselmi, ed. 58-86. Roma: Gangemi.

Marías, Fernando. 2017. “Definición y límites del mecenazgo: en singular, dual y plural, con la basílica del Pilar al fondo." En Del mecenazgo a las nuevas formas de promoción artística. Actas del XIV Coloquio de Arte Aragonés, Javier Ibáñez Fernández, editor, 103-142. Zaragoza: Universidad.

Marías, Fernando. 2017. "Ventura Rodríguez: proyectos y fábricas de catedrales." En Ventura Rodríguez. Arquitecto de la llustración, Delfín Rodríguez Ruiz, editor, 90-115. Madrid: Comunidad de Madrid.

Márquez Villanueva, Francisco. 2004. Santiago: trayectoria de un mito. Barcelona: Bellaterra. https://doi.org/10.24201/nrfh.v53i1.2265

Martínez Medina, Francisco J. 2015. Cristianos y musulmanes en la Andalucía moderna. La Granada del siglo XVI, una ciudad intercultural: Invenciones de reliquias y libros plúmbeos. PhD. diss., Universidad de Granada.

Martínez Molina, Javier. 2016. “La Ilustración, una edad de oro de la arquitectura aragonesa (1750-1808)." En Pasión por la libertad. La Zaragoza de los Pignatelli, Domingo J. Buesa Conde, editor, 314-355. Zaragoza: Ibercaja.

McNally, Robert E. 1959. "Christus in the pseudoisidorian Liber de ortu et obitu patriarcharum." Traditio, 21: 167-183. https://doi.org/10.1017/ s0362152900017682

McNally, Robert E. 1985. "Isidoriana." Theological Studies 20: 432-442.

Medina, F. de. B. 2001. "Pablo Diego Ibáñez." En Diccionario histórico de la Compañía de Jesús. Biográfico-temático, Charles E. O’Neil y Joaquín M ${ }^{\mathrm{a}}$ Domínguez Ortiz, editores, 1.118. Madrid: Universidad Pontificia de Comillas.

Morte García, Carmen. 2009. Damián Forment, escultor del Renacimiento. Zaragoza: Caja Inmaculada.

Muñoz Sancho, Ana M. a. 2014. "Aportación documental al proceso de ejecución del ornato escultórico de la Santa Capilla del Pilar de Zaragoza (1757-1768)." Artigrama 29: 385-412. 
Nagel, Alexandre, y Christopher Wood. 2010. Anachronic Renaissance. Nueva York: Zone Books.

Ortega Vidal, Javier, Sancho Gaspar, José Luis, y Francisco J. Marín Perellón. 2018. Ventura Rodríguez. El poder del dibujo, n. ${ }^{\circ} 11,136-151$. Madrid: Comunidad de Madrid.

Ortí, Montse. 2015. "La projecció catalana i europea del marbre brocatell de Tortosa." Recerca 16: 121-161.

Ortiz, Blas. 1549. Summi Templi Toletani [perquem graphica] descriptio. Toledo: Juan de Ayala.

Ostrow, Steven F. 1991. "Gialorenzo Bernini, Girolamo Lucenti, and the Statue of Philip IV in S. Maria Maggiore: Patronage and Politics in Seicento Rome." The Art Bulletin 73: 89-118. https://doi.org/10.2307/3045780

Pensabene, Patrizio. 1998. Marmi antichi ll. Cave e tecnica di lavorazione. Provenienze e distributione. Roma: L'Erma di Bretschneider.

Pensabene, Patrizio, Lazzarini, Lorenzo, De Nuccio, Marilda, and Lucrezia Ungaro, eds. 2002. I marmi colorati della Roma imperiale. Roma: Comune di Roma-Marsilio.

Reese, Thomas F. 1976. The Architecture of Ventura Rodríguez. Nueva York: Garland.

Rey Castelao, Ofelia. 1985. Historiografía del voto de Santiago: recopilación crítica de una polémica histórica. Santiago de Compostela: Universidad de Santiago.

Rey Castelao, Ofelia. 2006. Los mitos del apóstol Santiago. Vigo: Nigra Trea.

Rey Castelao, Ofelia. 2015. "Teresa, patrona de España." Hispania Sacra 67, 136: 531-573. https://doi.org/10.3989/hs.2015.016

Rincón García, Wifredo. 2000. El Pilar de Zaragoza. León: Everest.

Rincón García, Wifredo. 1991. "Tres vistas de Zaragoza del siglo XVII." En Velázquez y el arte de su tiempo, 299-308. Madrid: Alpuerto.

Ríos Balaguer, Teodoro. 1925-1926. "Algunos datos para la historia de las obras del actual Santo Templo Metropolitano de Nuestra Señora del Pilar de Zaragoza." Boletín del Museo provincial de Bellas Artes IX (11): 1-48 y 12: 49-79, doc. 30.

Rodríguez Ruiz, Delfín, ed. 2017. Ventura Rodríguez. Arquitecto de la llustración. Madrid: Comunidad de Madrid.

Román de la Higuera, Jerónimo. 1648. Auli Hali poetae burdigalensis, civisque toletani, De adventu in Hispanias S. Jacobi Zebedaei filii. Madrid: Diego Díaz de la Carrera.

Rowe, Erin K. 2005. Disrupting the Republic: Santiago, Teresa de Jesus, and the Battle for the Soul of Spain, 1617-1630, Ph.D. diss., The Johns Hopkins University.

Rowe, Erin K. 2011. Saint and Nation. Santiago, Teresa de Jesus, and Plural Identities in Early Modern Spain, 20-46. University Park: The Pennsylvania University Press. https://doi. org/10.1086/664145

Sante, Guido. 2013. "II Filippo IV di Gianlorenzo Bernini e Girolamo Lucenti." En Figure, liturgia e culto, arte. Ricerche dall'Archivio della Basilica Papale di Santa Maria Maggiore, Michal Jagosz, editor, 2, 213-236. Roma: Lisanti.

Santiago aquí, allá y acullá. Miscelánea de estudios jacobeos. 2004. Guadalajara: El Colegio de Jalisco, Guadalajara.

Serrano Martín, Eliseo. 2014. "Silentium facite: El fin de la polémica y el discurso en torno a la Virgen del Pilar en la Edad Moderna." Hispania 74 (248): 687-714. https://doi.org/10.3989/ hispania.2014.020

Serrano Martín, Eliseo. 2014. El Pilar, la historia y la tradición: la obra erudita de Luis Díez de Aux (1562-ca. 1630), Zaragoza: Mira.

Serrano Martín, Eliseo. 2015. "Milagros, devoción y política a propósito de la virgen del Pilar en la edad moderna." En Utopías, sueños y quimeras (España, siglos XVI y XVII) - Utopies, rêves et chimères (Espagne, XVle-XVIle siècles). Una encrucijada de sueños, e-Spania, https://journals.openedition.org/e-spania/24814. https:// doi.org/10.4000/e-spania.24814

Sotomayor y Muro, Manuel. 1979. "La Iglesia en la España romana: Antiguas tradiciones sobre los orígenes del cristianismo hispana." En Historia de la Iglesia en España. I: La Iglesia en la 
España romana y visigoda (siglos I-VIII), Ricardo García-Villoslada, editor. Madrid: Biblioteca de Autores Cristianos.

Tausiet Carlés, María. 2008. "Zaragoza celeste y subterránea. Geografía mítica de una ciudad (siglos XV-XVIII)." En L'imaginaire du territoire en Espagne et au Portugal (XVle-XVIle siècles), François Delpech, editor, 141-170. MadridParís: Casa de Velázquez.

Tropheos y antigüedades de la imperial ciudad de Zaragoza y general historia... Zaragoza: Sebastián de Cormellas.

Usón García, Ricardo. 1990. La intervención de Ventura Rodríguez en el Pilar. La Santa Capilla generatriz de un sueño arquitectónico. Zaragoza: Colegio Oficial de Arquitectos de Aragón.

Usón García, Ricardo. 2017. “La Santa Capilla del Pilar de Zaragoza." En Ventura Rodríguez. Arquitecto de la llustración, Delfín Rodríguez
Ruiz, editor, 314-319. Madrid: Comunidad de Madrid, Madrid.

Valderas, Alejandro. 2000. Bibliografía histórica leonesa: Juan de Ferreras García (1652/1735): estudio bio-bibliográfico, León: Universidad de León.

Van Liere, K. Elliott. 2006. "The Missionary and the Moorslayer: James the Apostle in Spanish Historiography from Isidore of Seville to Ambrosio de Morales." Viator 37: 519-543. https://doi.org/10.1484/j.viator.2.3017498

Villanueva, José de. 1723. Carta de Joseph de Villanueva, infantico de la Virgen del Pilar, a la muy Illustre Academia de Portugal, querellándose del escritor contra la tradición de la venida de Santiago a España, y la Divina Reina a Zaragoça, sin producir instrumento ni argumento nuevo y en ocasión tan importuna de estar estas materias decididas. ZaragozaMadrid. 